\title{
ESTUDO DA EVOLUÇÃO DA PAISAGEM DO QUADRILÁTERO FERRÍFERO (MINAS GERAIS, BRASIL) POR MEIO DA MENSURAÇÃO DAS TAXAS DE EROSÃO $\left({ }^{10} \mathrm{Be}\right)$ E DA PEDOGÊNESE ${ }^{(1)}$
}

\author{
César Augusto Chicarino Varajão(2), André Augusto Rodrigues Salgado(3), \\ Angélica Fortes Drummond Chicarino Varajão ${ }^{(4)}$, Régis Braucher ${ }^{(5)}$, Fabrice \\ Colin $^{(6)}$ \& Hermínio Árias Nalini Jr. ${ }^{(7)}$
}

\begin{abstract}
RESUMO
Geomorfologicamente o Quadrilátero Ferrífero é uma região conspícua, onde raízes de estruturas metassedimentares proterozóicas, apresentando feições de um relevo jovem, encontram-se em destaque sobre um mar de colinas de rochas cristalinas do Arqueano. O presente trabalho teve como objetivo o estudo da evolução da paisagem do Quadrilátero Ferrífero por meio da análise integrada dos dados quantitativos das taxas de erosão $\left({ }^{10} \mathrm{Be}\right)$ e dos tipos de perfis de solos desenvolvidos a partir dos principais litotipos da região. A mensuração da concentração de ${ }^{10}$ Be extraído do quartzo de veios, de quartzitos e de sedimentos fluviais foi obtida utilizando um espectrômetro de massa por acelerador. A razão média de erosão de $7 \mathrm{~m}$ por milhão de anos coloca em evidência um importante soerguimento epirogenético da região em estudo. Concordantemente, os estudos macromorfológicos, mineralógicos e micromorfológicos de todos os perfis de solos investigados por meio de trabalhos de campo, da difração de raios $\mathrm{X}$ e da microscopia óptica mostram perfis imaturos e autóctones. Esses resultados sugerem que o relevo do Quadrilátero Ferrífero é um produto de constante e intenso processo erosivo.
\end{abstract}

Termos de indexação: geomorfologia, neotectônica, taxa de erosão, solos imaturos, solos autóctones.

\footnotetext{
(1) Recebido para publicação em novembro de 2008 e aprovado em maio de 2009.

(2) Professor Associado, Departamento de Geologia, Escola de Minas, Universidade Federal de Ouro Preto - UFOP. Campus Morro do Cruzeiro, R. Diogo de Vasconcelos 122, CEP 35400-000 Ouro Preto (MG). E-mail: varajao@degeo.ufop.br

(3) Professor Adjunto, Departamento de Geografia, Instituto de Geociências, Universidade Federal de Minas Gerais - UFMG. Av. Presidente Antônio Carlos 6.627, Pampulha, CEP 31270-901 Belo Horizonte (MG). E-mail: geosalgado@yahoo.com.br

(4) Professor Associado, Departamento de Geologia, Escola de Minas, UFOP. E-mail: angelica@degeo.ufop.br

(5) Pesquisador do CNRS, CEREGE, Europôle de l'Arbois, Aix-em Provence, E-mail: braucher@cerege.fr

(6) Pesquisador do IRD-Institute pour le Dévelopemment de la Recherche. Nouméa, E-mail: Fabrice.colin@noumea.ird.nc

(7) Professor Associado, Departamento de Geologia, Escola de Minas, UFOP. E-mail: nalini@degeo.ufop.br
} 


\title{
SUMMARY: EVOLUTION OF THE LANDSCAPE IN THE REGION OF QUADRILÁTERO FERRÍFERO (MINAS GERAIS, BRAZIL) BASED ON THE MEASUREMENT OF EROSION RATES (10Be) AND PEDOGENESIS
}

\begin{abstract}
A geomorphological overview of the Quadrilátero Ferrifero reveals a conspicuous region where roots of metassedimentary Proterozoic strucutures, displaying young relief features, are in evidence over a sea of hills from the Archean basement. This paper deals with the landscape evolution in the "Quadrilátero Ferrifero" region, based on the integrated analysis of quantitative data of the erosion rates $\left({ }^{10} \mathrm{Be}\right)$ and of the soil types developed from the main rocks of the region. The ${ }^{10}$ Be concentration extracted from quartz of veins, quartzites and fluvial sediments was measured by a mass spectrometer (accelerator). The mean erosion ratio of $7 \mathrm{~m} \mathrm{Ma}^{-1}$ highlights a significant regional epirogenetic uplift. In agreement, the macromorphological, mineralogical and micromorphological studies of all soil profiles, investigated by field work, $X$ ray diffraction and optical microscopy, showed immature and autochthonous soils. These results suggest that the relief of the Quadrilátero Ferrifero is product of a constant and intense erosion process.
\end{abstract}

Index terms: geomorphology, neotectonic, erosion rate, immature soils, autochthonous soils.

\section{INTRODUÇÃO}

A questão da evolução da paisagem no Quadrilátero Ferrífero sempre foi motivo de grandes controvérsias. $\mathrm{O}$ modelado regional tem sido objeto de estudo desde os trabalhos de Hader \& Chamberlin (1915), para quem o relevo da região é fruto de sua estrutura e da erosão diferencial, onde os quartzitos e itabiritos constituem o substrato das terras altas, os xistos-filitos compreendem o substrato das terras de altitude mediana e as terras baixas estão moldadas sobre granito-gnaisses. Espacialmente, as terras altas constituem um conjunto de cristas e superfícies erosivas soerguidas que possuem uma forma grosseiramente quadrangular (Quadrilátero Ferrífero), formando o entorno das terras baixas, por onde corre o Rio das Velhas, nível de base da região central do Quadrilátero Ferrífero.

Outras considerações semelhantes acerca dessa conformação geomorfológica, controlada pela estrutura (dobras e falhas) e pela erosão diferencial, foram apresentadas em trabalhos posteriores, que investigaram o modelado local procurando compreender ciclos de erosão e aplainamento. Entre eles, destacamse os de King (1956), Barbosa \& Rodrigues (1965), Dorr (1969), Barbosa (1980) e Varajão (1991). Este último verificou que a quantidade de ciclos erosivos identificados em cada um dos trabalhos realizados anteriormente dependia do conceito que cada autor possuía acerca de superfície de aplainamento, bem como do intervalo altimétrico considerado. Desse modo, no que se refere à gênese da paisagem local, as conclusões sobre a erosão diferencial permanecem atualmente como as únicas de caráter consensual. Entretanto, quase todos os estudos que interpretaram a ação da erosão diferencial basearam-se em análises dedutivas, carentes de dados quantitativos.

Nota editor: $\mathrm{Ma}=$ mega anos $=$ milhões de anos.
No Quadrilátero Ferrífero, o primeiro trabalho que investigou a erosão diferencial com base na quantificação dos processos erosivos foi o de Salgado et al. (2004). Esses autores abordaram o tema por meio de análise química de amostras de água coletadas em nascentes e em canais fluviais de variadas ordens em diferentes litotipos. Os dados referentes aos sólidos totais dissolvidos nas amostras de água foram também utilizados para o cálculo da taxa anual de rebaixamento do relevo. Esse trabalho concluiu que a diferença de altitude em relação ao nível de base, bem como a área da bacia hidrográfica, são variáveis que influem na intensidade da denudação geoquímica no Quadrilátero Ferrífero. Além disso, demonstrou, quantitativamente, a existência de uma denudação geoquímica diferencial, em que: quartzitos/itabiritos (1,3-4 $\left.\mathrm{m} \mathrm{Ma}^{-1}\right)$ constituem as rochas mais resistentes; xistos/filitos (4-8 $\left.\mathrm{m} \mathrm{Ma}^{-1}\right)$ e granito-gnaisses $\left(5,5 \mathrm{~m} \mathrm{Ma}^{-1}\right)$, as de resistência mediana; e mármores e dolomitos $\left(25 \mathrm{~m} \mathrm{Ma}^{-1}\right)$, as de menor resistência. Esses resultados foram análogos aos encontrados por Reesman \& Godfrey (1981), que estudaram sub-bacias do Rio Tennessee. No entanto, considerando-se a denudação geoquímica em bacias de grandes dimensões, Pinet \& Soriau (1988) e Summerfield (1991) atestam que, além do substrato, da área da bacia e do nível de base, a tectônica também tem grande interferência na intensidade desse tipo de denudação. Nesse contexto, as bacias em áreas orogênicas possuem as maiores taxas de denudação, e as menores taxas ocorrem em áreas cratônicas.

Posteriormente, Salgado et al. (2007, 2008) chegaram a conclusões semelhantes utilizando como ferramenta o núcleo cosmogênico ${ }^{10} \mathrm{Be}$, isótopo radioativo com meia-vida de $1,5 \mathrm{Ma}$, para mensurar, a longo termo (1,5 Ma), taxas médias de erosão de superfícies e de bacias hidrográficas (Brown et al., 1995; Granger et al., 1996; Blanckenburg, 2005). Estes autores concluíram que o relevo do Quadrilátero Ferrífero é controlado pela litoestrutura e por 
processos de erosão diferencial e que as áreas que têm por substrato os quartzitos e itabiritos são muito mais resistentes à erosão do que aquelas moldadas sobre xistos-filitos e granito-gnaisses.

Esses recentes estudos quantitativos da erosão diferencial com ênfase na evolução do modelado no Quadrilátero ferrífero, apesar de terem sido realizados sobre os principais litotipos da região, utilizaram como base somente análise química de amostras de água coletadas em canais fluviais e a concentração de ${ }^{10} \mathrm{Be}$ em quartzo de veios, sedimentos e rochas. Nenhuma correlação foi efetuada com os perfis de solo desenvolvidos sobre esses diferentes litotipos e, consequentemente, com o seu papel na evolução da paisagem.

O presente artigo enfocou o estudo da evolução do modelado por meio da análise integrada dos dados quantitativos das taxas de erosão $\left({ }^{10} \mathrm{Be}\right)$ e dos tipos de perfis de solo desenvolvidos a partir dos principais litotipos do Quadrilátero Ferrífero. O conhecimento das principais transformações mineralógicas, micromorfológicas e geoquímicas, com a consequente liberação dos elementos químicos maiores (erosão geoquímica atual), leva ao entendimento do grau de maturidade dos diferentes perfis de solo e à compreensão das relações entre a erosão e a pedogênese na evolução da paisagem.

\section{O QUADRILÁTERO FERRÍFERO}

O Quadrilátero Ferrífero possui cerca de $7.200 \mathrm{~km}^{2}$ e localiza-se na parte central do Estado de Minas Gerais, na região Sudeste do Brasil (Figura 1), junto à borda sul do Craton do São Francisco (Almeida, 1977). O clima da região é tropical semiúmido, possuindo duas estações climáticas bem definidas: verão úmido e inverno seco. É constituído por quatro conjuntos litoestratigráficos (Alkmim \& Marshak, 1998): Complexos Metamórficos, compostos por terrenos granito-gnáissicos de idade arqueana; Supergrupo Rio das Velhas, formado por uma sequência vulcanosedimentar arqueana tipo "greenstone belt"; Supergrupo Minas, formado por metassedimentos clásticos e químicos de idade proterozoica; e Grupo Itacolomi, formado por metassedimentos clásticos proterozoicos (Figura 1). Toda a sequência é seccionada por diques máficos; a idade de $906 \mathrm{Ma}$ representa a principal época de intrusão desses diques (Silva et al., 1992).

O levantamento pedológico do Estado de Minas Gerais (CETEC, 1983) definiu três unidades de mapeamento para o Quadrilátero Ferrífero: (1) AR2, composta por Afloramentos de Rocha (AR), Cambissolos com A moderado e Solos Litólicos com A fraco, relacionados principalmente aos itabiritos do Grupo Itabira e aos quartzitos dos grupos Caraça e Itacolomi; (2) Cd3, formada por Cambissolos distróficos com A fraco, relacionados aos filitos do Grupo Piracicaba; e (3) LVAd3, constituída por Latossolos
Vermelho-Amarelos distróficos com A moderado, relacionados aos gnaisses do Complexo Bação e aos xistos do Grupo Nova Lima.

Essas mesmas classes de solos, mas com maior detalhamento dos diferentes tipos hierárquicos, foram mantidas na nova versão, em elaboração, do mapa de solos de Minas Gerais (1: 600.000 - FEAM/UFV Fundação Estadual do Meio Ambiente/Universidade Federal de Viçosa - Departamento de Solos), e a classe LVd8 (Latossolos Vermelhos Distróficos), relacionada aos xistos do Grupo Nova Lima, foi definida na região centro-sul do Quadrilátero Ferrífero. Finalmente, com relação aos solos sobre formações ferríferas, Camargo (1982) classificou como Latossolos Ferríferos (antiga denominação) perfis de solos desenvolvidos sobre pedimentos de rochas itabiríticas, e Costa (2003) identificou Latossolos Vermelhos originados de itabirito em diferentes localidades do Quadrilátero Ferrífero, sem, entretanto, correlacioná-los com a evolução da paisagem.

No que se refere à gênese dos perfis de solo no Quadrilátero Ferrífero, poucos estudos foram direcionados para esse fim. Particularmente, na porção sul do Complexo do Bação, onde ocorrem vertentes com baixa declividade, os solos desenvolvidos sobre gnaisses são Latossolos Vermelho-Amarelos distróficos (CETEC, 1983; Parsanese, 2001). Entretanto, estudos efetuados por Figueiredo et al. (2004), suportados por análises micromorfológicas, mostraram que os solos latossólicos são restritos aos segmentos de meia vertente e foram desenvolvidos a partir de materiais coluvionares provenientes dos perfis da alta vertente. Analogamente, Bacellar et al. (2005) designaram esses materiais situados na meia vertente como rampas de colúvio. Na alta e na baixa vertente os perfis são pouco desenvolvidos, sendo classificados, respectivamente, como Cambissolos Háplicos e Neossolos Litólicos e, ou, Flúvicos (Figueiredo et al., 2004). Estes autores relacionam esse processo à neotectônica durante o Pleistoceno Superior/Holoceno Médio, que leva ao encaixamento da rede de drenagem e propicia o fluxo gravitacional de sedimentos e sua deposição na meia vertente.

Evidências de coluvionamento foram também registradas previamente em depósitos argilosos cenozoicos ocorrentes nos sinclinais da Moeda (Varajão et al., 1989a,b, 1990, 2000a, 2001; Santos, 2003) e Dom Bosco (Varajão \& Santos, 2003; Santos et al., 2004; Santos \& Varajão, 2004), cujos substratos são filitos do Grupo Piracicaba. Esses depósitos foram formados em pequenas bacias relacionadas a eventos neotectônicos que teriam ocorrido no final do Oligoceno e início do Mioceno (Lipski et al., 2002). Com base em estudos micromorfológicos e cristaloquímicos, Varajão et al. (2001) e Santos (2003) descrevem a ocorrência de perfis pedogenéticos superpostos, sendo o perfil inferior formado in situ e o superior invertido, formado a partir dos sedimentos lateríticos coluvionares. Esses sedimentos coluvionares seriam oriundos dos perfis de solo desenvolvidos sob condições de clima quente e 
úmido (Neo-Eoceno ao Eoceno Superior), que levou à formação de espessa cobertura laterítica sobre xistos e filitos.

\section{MATERIAL E MÉTODOS}

As amostras de quartzo para o cálculo de taxas de erosão $\left({ }^{10} \mathrm{Be}\right)$ foram coletadas em veios de quartzo, gnaisses e quartzitos, localizados no topo de colinas, $\mathrm{e}$ em sedimentos fluviais das diferentes sub-bacias (Figura 1). Os veios de quartzo foram utilizados pelo fato de que este mineral, além de abundante na superfície terrestre, pode ser facilmente purificado e dissolvido para extração laboratorial do ${ }^{10} \mathrm{Be}$, além de possuir uma estrutura cristalográfica que minimiza a contaminação do ${ }^{10} \mathrm{Be}$ produzido in situ pelo ${ }^{10} \mathrm{Be}$ atmosférico, bem como sua perda para a atmosfera (Braucher et al., 2003; Brown et al., 2003). As amostras foram coletadas no topo das colinas para evitar áreas que possam ter sido recobertas por colúvios, fato que alteraria a incidência de radiação cósmica sobre a amostra.

Para a análise do ${ }^{10} \mathrm{Be}$, as amostras (cerca de $70 \mathrm{~g}$ ) foram primeiramente trituradas e reduzidas nas frações entre 1 e $0,25 \mathrm{~mm}$. Em seguida, o quartzo foi purificado e extraído, utilizando uma solução de aproximadamente $100 \mathrm{~mL}$ de $\mathrm{HCl}$ concentrado e $\mathrm{H}_{2} \mathrm{SiF}_{6}$ para extinguir os demais minerais. Para eliminação do ${ }^{10} \mathrm{Be}$ atmosférico nas amostras de quartzo puro, foram adicionadas três soluções de $20 \mathrm{~mL}$ de HF concentrado, em intervalos de 24 h entre cada uma. $\mathrm{Na}$ sequência, o quartzo purificado foi dissolvido em $100 \mathrm{~mL}$ de HF concentrado. Nesta solução contendo quartzo dissolvido, foi acrescentado $0,3 \mathrm{~g}$ de ${ }^{9} \mathrm{Be}$. Extrações químicas sucessivas com base em solventes e precipitações foram realizadas como forma de recuperar o ${ }^{10} \mathrm{Be}$, que então foi mensurado no espectrômetro de massa Tandétron AMS em Gif-sur-Yvette, França. As razões medidas ${ }^{10} \mathrm{Be} /{ }^{9} \mathrm{Be}$ foram calibradas com o material-padrão de referência SRM 4325 do NIST (National Institute of Standards and Technology), usando a razão ${ }^{10} \mathrm{Be} /{ }^{9} \mathrm{Be}$ de $(26,8 \pm 1,4) \times 10^{-12}$. A percentagem de erro do método de mensuração do ${ }^{10} \mathrm{Be}$ inclui $3 \%$ referentes à passagem do elemento no acelerador, $1 \%$ de erro estatístico na contagem do elemento e $6 \%$ na produção in situ no quartzo amostrado (Stone, 2000). Após esses procedimentos, foi possível calcular as taxas de erosão, devido ao fato de que estas são funções da produção de ${ }^{10} \mathrm{Be}$, da altitude, da profundidade, da latitude e da sombra proporcionada pelo relevo. A primeira dessas variáveis foi mensurada no espectrômetro de massa, e as outras quatro foram medidas em campo na coleta das amostras (Blanckenburg, 2005).

Os solos foram descritos e as amostras coletadas em todos os horizontes a partir dos diferentes litotipos, nas mesmas sub-bacias (Figura 1) das amostragens de água efetuadas por Salgado et al. (2004). Foram coletadas amostras deformadas para análise mineralógica e química total e amostras indeformadas para o estudo micromorfológico. As lâminas foram descritas utilizando a terminologia de Brewer (1976), no que diz respeito às características pedológicas, e segundo Spry (1969), no que tange às rochas metamórficas.

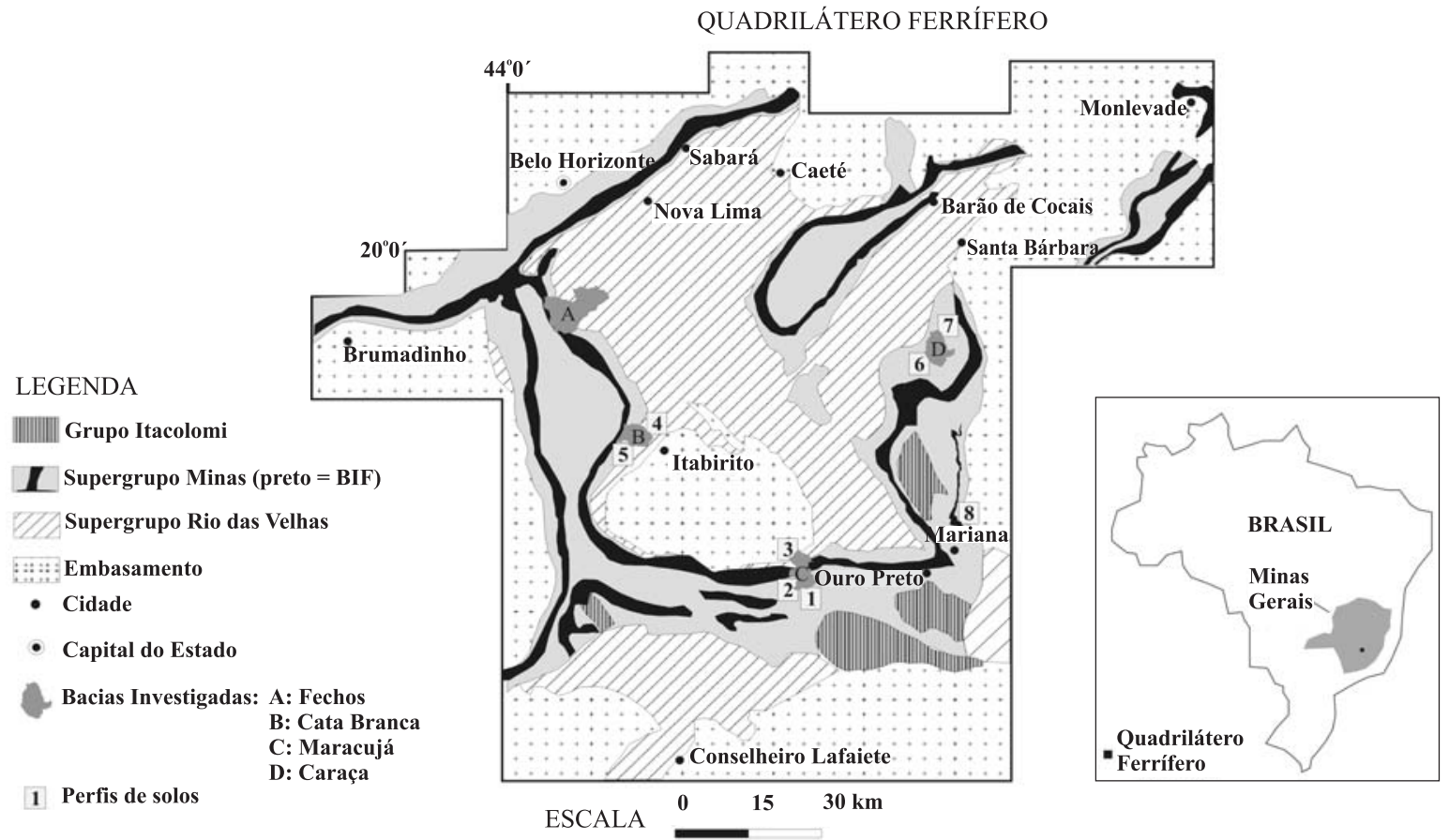

Figura 1. Mapa geológico do Quadrilátero Ferrífero (Modificado de Alkmim \& Marshak, 1998) com a localização das bacias investigadas. 
As análises químicas totais dos elementos maiores $\mathrm{Al}, \mathrm{Si}, \mathrm{Fe}, \mathrm{Mg}, \mathrm{Ca}, \mathrm{Na}$ e $\mathrm{K}$ e do menor $\mathrm{Mn}$ foram realizadas via Espectrometria de Emissão Atômica por Plasma (ICP-OES Spectro Cirus CCD).

Nas análises mineralógicas utilizou-se o difratômetro RIGAKU GEIGERFLEX D/MAX com radiação monocromática de $\mathrm{CuK} \alpha$ e velocidade do goniômetro de $1.2^{\circ} 2 \theta \mathrm{min}^{-1}$ para a fração pó total e para a fração argila (fração $<2 \mu \mathrm{m}$ ) separada por sedimentação. Os difratogramas obtidos na fração total abrangem um intervalo de 2 a $70^{\circ}(2 \theta)$, e nas amostras orientadas da fração argila, de 2 a $35^{\circ}(2 \theta)$.

\section{RESULTADOS}

\section{Taxas de erosão}

As taxas de erosão obtidas pelo método ${ }^{10} \mathrm{Be}$ em amostras de superfície e sedimentos no Quadrilátero Ferrífero encontram-se no quadro 1 . Os resultados revelam que elas variam segundo os diferentes litotipos. Os quartzitos $\left(0,3-2,5 \mathrm{~m} \mathrm{Ma}^{-1}\right)$ apresentam as taxas de erosão mais baixas, seguidos por filitos (4-5,5 m Ma$\left.{ }^{-1}\right)$, gnaisses $\left(12-13 \mathrm{~m} \mathrm{Ma}^{-1}\right)$ e xistos $\left(12,5-14,5 \mathrm{~m} \mathrm{Ma}^{-1}\right)$. Os sedimentos do exutório da bacia de Fechos (Quadro 1), contendo a contribuição de diferentes litotipos (itabirito, quartzito, mármore, dolomito, xisto e filito), mostram uma taxa de erosão de $6,8 \mathrm{~m} \mathrm{Ma}^{-1}$. Assim, este valor pode ser considerado o valor médio da erosão no Quadrilátero Ferrífero no último milhão de anos.

\section{Estudo dos perfis de solo dos principais litotipos do Quadrilátero Ferrífero}

Os perfis de solos estudados relacionam-se aos filitos das formações Batatal e Fecho do Funil (Supergrupo Minas), aos xistos dos grupos Sabará (Supergrupo Minas) e Nova Lima (Supergrupo Rio das Velhas), aos itabiritos da Formação Cauê (Grupo Itabira, Supergrupo Minas), aos quartzitos do Grupo Caraça (Supergrupo Minas), aos gnaisses do

Quadro 1. Taxas de erosão no Quadrilátero Ferrífero medidas pelo método ${ }^{10} \mathrm{Be}$

\begin{tabular}{|c|c|c|c|c|}
\hline Ponto & Profundidade & $\begin{array}{l}\text { Produção de } \\
{ }_{10} \mathrm{Be}\left(\text { at g }^{-1}\right)\end{array}$ & $\begin{array}{l}\text { Taxa de } \\
\text { erosão }\end{array}$ & Referência \\
\hline & $\mathrm{m}$ & \multicolumn{3}{|c|}{$\mathrm{m} \mathrm{Ma}^{-1}$} \\
\hline & & \multicolumn{3}{|l|}{ Medidas em superfície } \\
\hline $\begin{array}{l}\text { 1A- Quartzito (Cercadinho) na } \\
\text { cabeceira do Maracujá }\end{array}$ & 0,00 & 2.928 .072 & $1,71 \pm 0,20$ & Salgado et al., 2007 \\
\hline $\begin{array}{l}\text { 1B- Quartzito (Cercadinho) na } \\
\text { cabeceira do Maracujá }\end{array}$ & 0,00 & 2.086 .715 & $2,58 \pm 0,26$ & Salgado et al., 2007 \\
\hline 2A- Filito (Piracicaba) no Maracujá & 0,00 & 1.172 .615 & $4,32 \pm 0,68$ & Salgado et al., 2007 \\
\hline 2B- Filito (Piracicaba) no Maracujá & 0,60 & 530.754 & $3,93 \pm 0,88$ & Salgado et al., 2007 \\
\hline 2C- Filito (Piracicaba) no Maracujá & 1,80 & 168.229 & $4,92 \pm 0,78$ & Salgado et al., 2007 \\
\hline 4A- Xistos Nova Lima (Mariana) & 0,00 & 348.389 & $12,64 \pm 3,75$ & Inédito \\
\hline 4C- Xistos Nova Lima (Mariana) & 2,00 & 60.339 & $14,44 \pm 3,30$ & Inédito \\
\hline $\begin{array}{c}\text { 5A- Caraça (quartzito) - afloramento } \\
\text { na alta bacia - Bocaina }\end{array}$ & 0,00 & 372.632 & $0,90 \pm 0,14$ & Inédito \\
\hline $\begin{array}{l}\text { 5B- Caraça (quartzito) - afloramento } \\
\text { na média bacia }\end{array}$ & 0,00 & 136.648 & $2,51 \pm 0,22$ & Inédito \\
\hline $\begin{array}{c}\text { 5C- Caraça (quartzito) - afloramento } \\
\text { na baixa bacia }\end{array}$ & 0,00 & 260.750 & $0,80 \pm 0,06$ & Inédito \\
\hline \multirow{3}{*}{$\begin{array}{l}\text { 5D- Caraça (quartzito) - afloramento } \\
\text { próximo a Cascatinha }\end{array}$} & 0,00 & 113.314 & $2,75 \pm 0,23$ & Inédito \\
\hline & $\begin{array}{l}\text { Produção de } \\
{ }^{10} \text { Be }(\text { M at g g })\end{array}$ & $\begin{array}{c}\text { Taxa de } \\
\left.\text { erosão }(\mathbf{m ~ M a})^{-1}\right)\end{array}$ & \multicolumn{2}{|c|}{ Referência } \\
\hline & & Medidas em sedimentos & & \\
\hline 6A- Filitos Piracicaba & $6.60 \pm 1.49$ & $7.95 \pm 1.86$ & \multicolumn{2}{|c|}{ Salgado et al., 2006, 2007, 2008} \\
\hline 6B- Filitos Piracicaba & $4.60 \pm 1.75$ & $11.82 \pm 5.54$ & \multicolumn{2}{|c|}{ Salgado et al., 2006, 2007, 2008} \\
\hline 7- Granito-gnaisse & $4.24 \pm 0.59$ & $12.92 \pm 1.97$ & \multirow{2}{*}{\multicolumn{2}{|c|}{$\begin{array}{l}\text { Salgado et al., 2006, 2007, } 2008 \\
\text { Salgado et al., 2006, } 2008\end{array}$}} \\
\hline 8A- Quartzito & $51.86 \pm 4.10$ & $0.29 \pm 0.03$ & & \\
\hline 8B- Quartzito & $29.22 \pm 7.59$ & $0.74 \pm 0.20$ & \multicolumn{2}{|c|}{ Salgado et al., 2006, 2008} \\
\hline 8C- Quartzito & $20.70 \pm 1.30$ & $2.35 \pm 0.20$ & \multicolumn{2}{|c|}{ Salgado et al., 2006, 2008} \\
\hline $\begin{array}{l}\text { 9- Bacia do Fecho (itabirito, } \\
\text { quartzito, mármores, dolomitos, } \\
\text { xistos e filitos) }\end{array}$ & $8.15 \pm 1.19$ & $6.84 \pm 0.85$ & \multicolumn{2}{|l|}{ Inédito } \\
\hline
\end{tabular}

$\mathrm{M}$ at $\mathrm{g}^{-1}=$ mega átomos por grama. 
embasamento (Complexo do Bação) e aos diques de metadiabásios (Figura 1, Quadro 2).
Perfil 1: Xisto do Grupo Sabará - O perfil de solo formado sobre esta unidade (Figura 2a) é pouco

\section{Quadro 2. Descrição macroscópica dos perfis de solos dos litotipos selecionados}

\begin{tabular}{|c|c|c|c|c|}
\hline Horiz. & Prof. & Amostra & Cor & Estruturas e outros atributos morfológicos \\
\hline & $\mathrm{cm}$ & & & Perfil 1 - Xisto do Grupo Sabará \\
\hline A & $0-30$ & $\mathrm{~S} 1$ & $7.5 \mathrm{YR} 5 / 6$ & $\begin{array}{l}\text { Pedregosidade acentuada, representada por litorrelíquias ferruginizadas, } \\
\text { centimétricas disseminadas em uma matriz franco-argilo-siltosa. Possui raízes } \\
\text { que persistem no horizonte inferior. }\end{array}$ \\
\hline $\mathrm{C}$ & $30->180$ & $\begin{array}{l}\text { S2 } \\
\text { S3 } \\
\text { S4 }\end{array}$ & $\begin{array}{l}7.5 \mathrm{YR} 5 / 8 \\
7.5 \mathrm{YR} 4 / 4 \\
7.5 \mathrm{YR} 7 / 6\end{array}$ & $\begin{array}{l}\text { Saprolito com estrutura de xistosidade do xisto preservada, mostrando } \\
\text { variações de tonalidade concordante com a estrutura. }\end{array}$ \\
\hline A & $0-30$ & B1 & $5 Y 7 / 4$ & $\begin{array}{l}\text { Perfil } 2 \text { - Filito da Formação Batatal } \\
\text { Pedregosidade acentuada representada por litorelíquias centimétricas de } \\
\text { filito, disseminadas em uma matriz franco-argilo-siltosa. Possui raízes. }\end{array}$ \\
\hline $\mathrm{C}$ & $30->130$ & $\mathrm{~B} 2$ & $5 \mathrm{Y} 7 / 1$ & Saprolito com estrutura de xistosidade do filito preservada. \\
\hline $\mathrm{A}$ & $0-10$ & F1 & $5 Y 7 / 1$ & $\begin{array}{l}\text { Perfil } 3 \text { - Filito da Formação Fecho do Funil } \\
\text { Horizonte A fraco com transição gradual para B. Presença de litorelíquias de } \\
\text { filito de aproximadamente } 0.5 \mathrm{~cm} \text { de diâmetro com estrutura de xistosidade } \\
\text { preservada e de raízes que persistem nos horizontes inferiores. }\end{array}$ \\
\hline $\mathrm{B}$ & $10-40$ & $\mathrm{~F} 2$ & $5 \mathrm{Y} 7 / 3$ & $\begin{array}{l}\text { Presença de litorrelíquias de filito de aproximadamente } 0.5 \mathrm{~cm} \text { de diâmetro } \\
\text { com estrutura de xistosidade preservada, disseminadas numa matriz franco- } \\
\text { argilo-siltosa amarelo-clara. Transição abrupta para o horizonte C. }\end{array}$ \\
\hline $\mathrm{C}$ & $40->135$ & F3 & $5 \mathrm{Y} 8 / 1$ & Saprolito com estrutura de xistosidade do filito preservada. \\
\hline A & $0-15$ & NL1 & 7.5YR $3 / 4$ & $\begin{array}{l}\text { Perfil 4 - Xisto do Grupo Nova Lima } \\
\text { Horizonte A fraco, argiloso, com muitas raízes que persistem no horizonte B. }\end{array}$ \\
\hline $\mathrm{B}$ & $15-60$ & NL2 & $7.5 \mathrm{YR} 4 / 6$ & $\begin{array}{l}\text { Horizonte argiloso bruno-forte com raízes. Transição gradual para CB, } \\
\text { caracterizada pelo aparecimento e incremento em quantidade e tamanho de } \\
\text { fragmentos de xisto e diminuição da matriz. }\end{array}$ \\
\hline $\mathrm{CB}$ & $60-180$ & NL3 & $\begin{array}{l}\mathrm{N} 4 / 0 \\
7.5 \mathrm{YR} 4 / 6\end{array}$ & $\begin{array}{l}\text { Fragmentos decimétricos residuais de xisto de coloração cinza disseminados } \\
\text { em uma matriz bruno-forte. Passagem gradacional para C. }\end{array}$ \\
\hline $\mathrm{C}$ & $180->300$ & NL4 & $\begin{array}{l}\text { N5/0 } \\
7.5 \mathrm{YR} 4 / 6\end{array}$ & $\begin{array}{l}\text { Horizonte } \mathrm{C} \text { com foliação bem evidenciada, de tonalidade bruno-escuro ( } 7.5 \mathrm{YR} \\
3 / 4) \text { com camadas cinza }(\mathrm{N} 5 / 0) \text {. }\end{array}$ \\
\hline A & $0-23$ & $\mathrm{E} 1$ & $7,5 \mathrm{YR} 6 / 4$ & $\begin{array}{l}\text { Perfil } 5 \text { - Gnaisse do Embasamento (Complexo do Bação) } \\
\text { Horizonte A fraco com minerais primários e raízes que persistem até o } \\
\text { horizonte C. }\end{array}$ \\
\hline $\mathrm{AB}$ & $23-48$ & - & $7.5 \mathrm{YR} 6 / 6$ & $\begin{array}{l}\text { Intensa bioturbação com fissuras verticalizadas. Fraca e esparsa ocorrência de } \\
\text { litorrelíquias milimétricas da rocha parental gnáissica. }\end{array}$ \\
\hline $\mathrm{B}$ & $48-91$ & $\mathrm{E} 2$ & $7,5 \mathrm{YR} 5 / 6$ & $\begin{array}{l}\text { Horizonte franco-argilo-siltosa. Litorrelíquias milimétricas a centimétricas de } \\
\text { cor rosada ( } 7.5 \text { YR } 8 / 4) \text { da rocha parental gnáissica. }\end{array}$ \\
\hline $\mathrm{C}$ & $91-+200$ & E3 & $\begin{array}{l}7.5 \mathrm{YR} 8 / 4 \\
7.5 \mathrm{YR} 6 / 6\end{array}$ & $\begin{array}{l}\text { Foliação gnáissica incipiente de cor rosada com manchas amarelo- } \\
\text { avermelhadas. }\end{array}$ \\
\hline A & $0-13$ & D1 & $2.5 \mathrm{YR} 3 / 4$ & $\begin{array}{l}\qquad \text { Perfil } 6 \text { - Metadiabásio } \\
\text { Horizonte A incipiente, friável e com muitas raízes que persistem até o } \\
\text { horizonte inferior. }\end{array}$ \\
\hline $\mathrm{B}$ & $13-120$ & $\begin{array}{l}\text { D2 } \\
\text { D3 }\end{array}$ & $\begin{array}{l}2.5 \mathrm{YR} 4 / 6 \\
2.5 \mathrm{YR} 5 / 4\end{array}$ & $\begin{array}{l}\text { Horizonte B argiloso com incipientes litorrelíquias disseminadas, com alguma } \\
\text { orientação parental preservada. }\end{array}$ \\
\hline $\mathrm{C}$ & $120-+300$ & $\mathrm{D} 4$ & $2.5 \mathrm{YR} 5 / 8$ & Saprolito com estrutura de foliação preservada. \\
\hline A & $0-5$ & - & $7.5 \mathrm{YR} 3 / 4$ & $\begin{array}{l}\text { Perfil } 7 \text { - Itabirito da Formação Cauê } \\
\text { Horizonte A fraco, com pedregosidade formada por fragmentos de itabirito }\end{array}$ \\
\hline $\mathrm{C}$ & $5-40$ & IT2 & 7.5 YR $5 / 8$ & Horizonte $\mathrm{C}$ com estrutura bandada do itabirito. \\
\hline A & $0-12$ & Q1 & $2.5 \mathrm{YR} 4 / 4$ & $\begin{array}{c}\text { Perfil 8 - Quartzito do Grupo Caraça } \\
\text { Horizonte A fraco, franco-siltoso, transição irregular gradual. }\end{array}$ \\
\hline B & $12-42$ & Q2 & $2.5 \mathrm{YR} 7 / 6$ & Horizonte B incipiente, franco-siltoso, com palhetas de mica. Transição gradual. \\
\hline $\mathrm{C}$ & $42-+75$ & Q3 & $2.5 \mathrm{YR} 8 / 6$ & Saprolito com estrutura de xistosidade preservada pelos níveis micáceos. \\
\hline
\end{tabular}


desenvolvido, sendo representado na base por um horizonte $\mathrm{C}$ bem espesso, com estrutura de xistosidade bem preservada, e transição gradual para o horizonte A. Foi classificado como Neossolo Regolítico (Embrapa, 2006).

Macroscopicamente, além da evidente foliação apresentada pelo horizonte $\mathrm{C}$, uma marcante variação de tonalidade, concordante com essa estrutura, reflete uma variação textural e mineralógica da rocha original. De fato, estudos microscópicos da rocha fresca, obtidos por meio de furos de sondagem, mostram ser essa foliação caracterizada pela presença de clorita, mica (moscovita), em associação com quartzo e pirita. Variações na distribuição e no tamanho desses constituintes refletem a variação textural e de tonalidade apresentada no horizonte C (Figura 2b), onde impregnações por óxido (hematita) e hidróxido (goethita) de ferro, concordantes com a foliação, são originadas da exsudação do ferro quando da alteração da clorita e dos minerais opacos (pirita), embora não mais presentes neste horizonte. Nas micas, são frequentes feições de ilitização e caulinização nas bordas e nos planos de clivagem. A variação no tamanho dos constituintes é notável para os grãos de quartzo, cujas formas são variáveis e os tamanhos podem atingir até $2 \mathrm{~mm}$. Adicionalmente, os contornos irregulares, com fortes reentrâncias, sugerem reações de dissolução (Figura $2 \mathrm{~h}$ ).

O horizonte A (Quadro 2, amostra S1) caracterizase micromorfologicamente por um fundo matricial formado por agregados com foliação residual em associação com agregados sem estrutura, constituídos por um esqueleto quartzoso, cujos grãos têm forma e tamanhos irregulares, semelhante aos do topo do horizonte precedente (horizonte C). Adicionalmente, nódulos ferruginosos de formas e tamanhos $(<0,8 \mathrm{~mm}$ ) variados encontram-se associados. Todos esses constituintes encontram-se imersos em um plasma de estrutura silassépica constituída por caulinita, ilita, goethita, hematita e gibbsita. O sistema de poros, com fissuras transagregados e interagregados, de largura até $0,5 \mathrm{~mm}$, embora não preenchidas, caracteriza a atuação pedogenética neste horizonte.

Perfil 2: Filito da Formação Batatal - Analogamente ao perfil desenvolvido sobre o xisto Sabará, o perfil de solo formado sobre esta unidade (Quadro 2) é pouco desenvolvido, sendo representado na base por um horizonte $\mathrm{C}$ bem espesso, com estrutura de xistosidade bem evidenciada e transição gradual para o horizonte A. Foi classificado, também, como Neossolo Regolítico (Embrapa, 2006).

A amostra de rocha fresca (furo de sondagem) é caracterizada por uma foliação marcante, que microscopicamente é definida pela presença de mica (moscovita), intercalada com grafita, quartzo e pirita. Localmente, a foliação é cortada por um veio de quartzo policristalino.
No horizonte C (amostras B3 e B2), a foliação, bem marcada pela presença de micas, persiste, ocorrendo feições de ilitização e caulinização nas bordas e nos planos de clivagem. Adicionalmente, observa-se uma variação textural dos minerais micáceos, caracterizada por alternância de níveis milimétricos (3 a $9 \mathrm{~mm}$ ) com textura fina $(<100 \mu \mathrm{m})$, intercalada com bandas mais finas $(0,5$ a $3 \mathrm{~mm})$ de textura mais grosseira $(>200 \mu \mathrm{m})$, definindo uma estrutura bandada.

No horizonte A (Quadro 2, amostra B1), o fundo matricial apresenta partes mais ferruginizadas e partes deferruginizadas. Ambas apresentam porções relíquas dos filitos precedentes em contato difuso com um plasma silassépico de composição: caulinita, ilita, goethita, hematita e gibbsita. Grãos de quartzo esparsamente distribuídos, analogamente ao horizonte C precedente, caracterizam uma estrutura porfirogrânica. O sistema de poros, com fissuras transagregados e interagregados, de largura até $0,6 \mathrm{~mm}$, embora não preenchidas, caracteriza a atuação pedogenética neste horizonte.

Perfil 3: Filito da Formação Fecho do Funil - O perfil de solo formado sobre esta unidade (Quadro 2) é também pouco desenvolvido (Figura 2c), sendo classificado como Cambissolo Háplico (Embrapa, 2006). É representado na base por um horizonte $\mathrm{C}$ de tonalidade cinza-clara que é sotoposto por um horizonte B pouco espesso $(\sim 30 \mathrm{~cm})$ com transição gradual para um horizonte A.

Estudos microscópicos da rocha fresca (R), moscovita-quartzo-xisto, obtida por meio de furos de sondagem, mostram que a foliação é caracterizada pela presença de níveis de quartzo, por vezes policristalino, com granulação variada $(<1 \mathrm{~mm})$ e extinção ondulante, intercalados com níveis de micas e de minerais opacos $(<10 \%)$.

O horizonte C (amostra F3) apresenta foliação evidenciada pela presença predominante de sericita em palhetas muito pequenas $(<5 \mu \mathrm{m})$, caracterizando uma estrutura lepidoblástica. Essas palhetas encontram-se associadas com feldspatos, que mostram intensas feições de seritização e caulinização nas bordas e nos planos de clivagem, além de conterem impregnações ferruginosas de composição goethítica e hematítica, originada pela exsudação do Fe dos minerais opacos, o que evidencia ainda mais a foliação presente. Os grãos de quartzo são raros e de tamanho $<100 \mu \mathrm{m}$. Uma intensificação da impregnação ferruginosa é observada em direção ao topo, mascarando as estruturas relíquas e marcando a transição para o horizonte B.

O horizonte B (Figura 2d) é caracterizado pela presença de litorrelíquias de filito $(1 \mathrm{~mm}$ a $0,5 \mathrm{~cm})$, com foliação marcada por impregnações ferruginosas, litorrelíquias de quartzito $(1 \mathrm{~mm})$ de forma irregular e pedorrelíquias com estrutura não diferenciada, com tamanhos e formas variadas ( $200 \mu \mathrm{m}$ a $1 \mathrm{~mm})$. São frequentes também os fragmentos de quartzo 

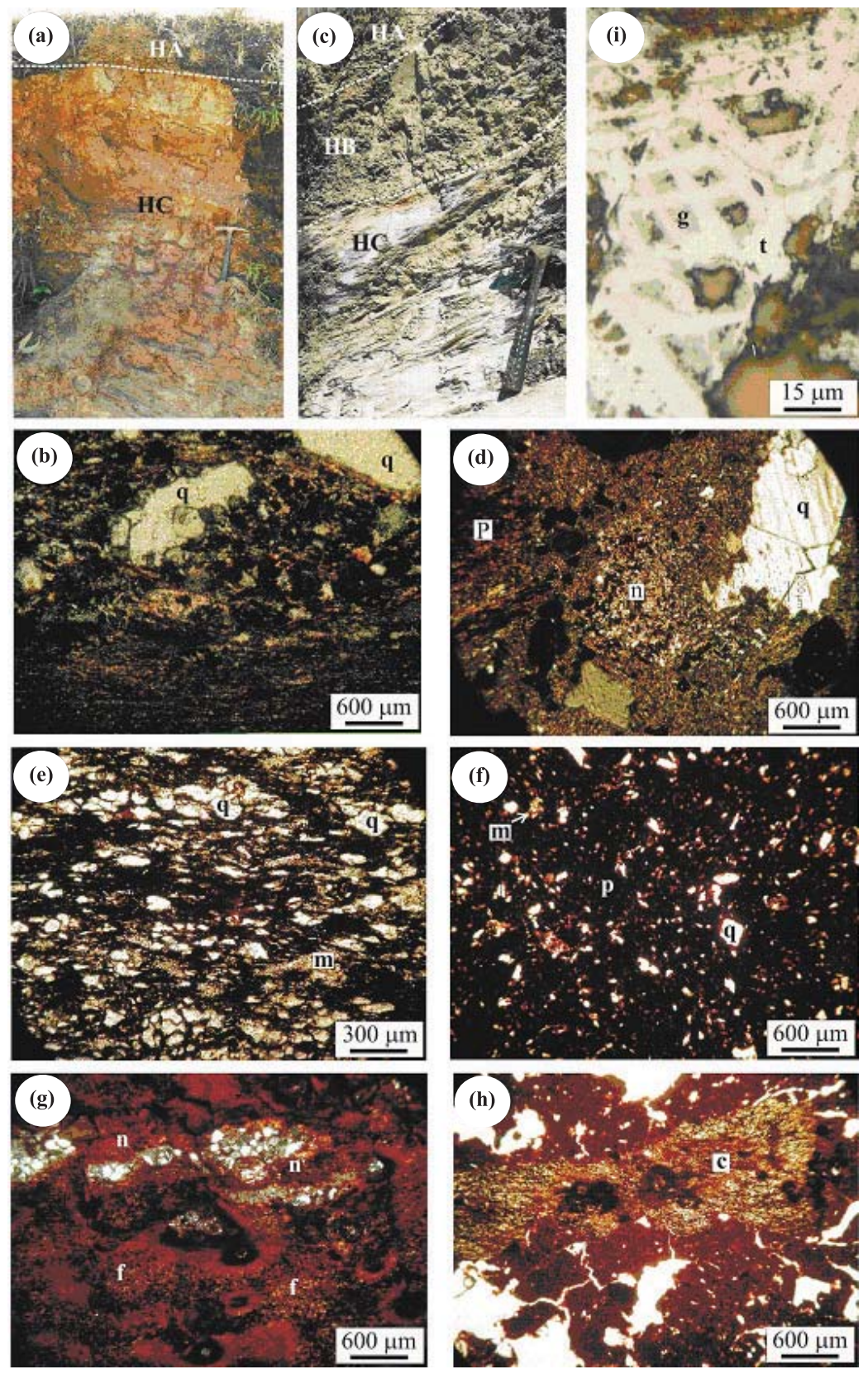

Figura 2. (A) e (B): Xisto do Grupo Sabará. (A) Horizontes A e C. (B) Fotomicrografia ao microscópio óptico (nicóis cruzados) do horizonte $\mathrm{C}$ (amostra S2) mostrando a variação textural e mineralógica evidenciada pela concentração de palhetas de moscovita na base e de quartzo (q) no topo; notar as reentrâncias de dissolução nos grãos de quartzo. (C) e (D): Filito do Grupo Piracicaba. (C) Horizontes A, B e C. (D) Fotomicrografia ao microscópio óptico (nicóis cruzados) do horizonte $B$ mostrando a presença de litorrelíquias (n) e grãos de quartzo (q) envolvidos por um plasma silassépico (p). (E) e (F): Xisto do Grupo Nova Lima. (E) Fotomicrografia ao microscópio óptico (nicóis cruzados) do horizonte C mostrando a foliação definida por finas intercalações de quartzo (q) e minerais foliares (caulinita, moscovita) com impregnações por óxidos e hidróxidos de ferro. (F) Fotomicrografia ao microscópio óptico (nicóis cruzados) do horizonte $B$ mostrando a estrutura porfirogrânica formada por grãos de quartzo e palhetas de mica (m), ambos disseminados num plasma argiloferruginoso (p). (G) e (H): Metadiabásio. (G) - Fotomicrografia do horizonte $\mathbf{C}$ mostrando as feições residuais da rocha original, representada por feldspatos intensamente caulinizados (f), em associação com nódulos lito e pedorrelíquias (n) com quartzo no interior. (H) - Fotomicrografia do horizonte B mostrando feições residuais totalmente caulinizadas (c) e ferruginizadas em contato difuso com o plasma castanho-avermelhado. (I) - Fotomicrografia do horizonte C desenvolvido a partir do itabirito da Formação Cauê (Grupo Itabira), mostrando a transformação um cristal de magnetita em martita (t) e os núcleos residuais de maghemita $(g)$. 
policristalinos de tamanho $(40 \mu \mathrm{m}$ a $1 \mathrm{~mm})$ e formas variadas. Esses constituintes, juntamente com algumas palhetas mais desenvolvidas de mica, constituem o esqueleto, que se encontra envolvido por um plasma silassépico de composição: caulinita, ilita gibbsita, goethita e feldspato.

A passagem do horizonte B para o horizonte A é marcada apenas pela presença de fissuras inter e transagregados, contendo, localmente, matéria orgânica. Os mesmos constituintes do esqueleto descritos no horizonte B encontram-se no horizonte A.

A presença de litorrelíquias e de grandes fragmentos de quartzo nos horizontes $\mathrm{B} \mathrm{e} \mathrm{A}$ (que diferem daqueles descritos no horizonte $\mathrm{C}$ ) pode inicialmente sugerir uma descontinuidade do horizonte $\mathrm{C}$ para os horizontes B e A. Assim, os horizontes B e A seriam coluvionares. Entretanto, como a rocha fresca revela uma variação mineralógica e textural, representada por níveis mais enriquecidos em quartzo e de tamanhos variados, intercalados com níveis predominantemente filossilicáticos, uma evolução in situ não pode ser descartada. Situação semelhante ocorre no perfil desenvolvido sobre os xistos do Grupo Sabará, anteriormente descrito, onde a transição entre os horizontes $\mathrm{C}$ e A é bem marcada pela variação textural e mineralógica apresentada por essa unidade, evidenciando uma evolução in situ do horizonte A.

Perfil 4: Xisto do Grupo Nova Lima - Similarmente ao perfil Fecho do Funil, o perfil de solo formado sobre esta unidade (Quadro 2) é pouco desenvolvido, sendo também classificado como Cambissolo Háplico (Embrapa, 2006).

Estudos microscópicos da rocha fresca, obtida por meio de furo de sondagem, classificam-na como um xisto com foliação bem marcada pela presença de clorita e mica (moscovita) com níveis micrométricos de quartzo $(<200 \mu \mathrm{m})$. É frequente a presença de opacos (pirita) distribuídos aleatoriamente. Observamse ainda intercalações mais espessas de quartzo em associação com ankerita, caracterizando a estrutura bandada desta rocha.

No horizonte C (NL4), a foliação ainda presente é definida por finas intercalações de quartzo e minerais foliares (caulinita, moscovita), sendo evidenciada por impregnações de óxidos (hematita) e hidróxidos (goethita) de ferro, originados da exsudação do ferro quando da alteração de clorita presente na rocha original, porém totalmente alterada neste horizonte (Figura 2e).

A transição entre os horizontes C e B (NL3) é caracterizada por um truncamento da foliação, apresentando fragmentos de filito com tamanhos e formas variadas, intensamente impregnados por ferro, mas que não possuem a mesma orientação da foliação, sugerindo uma remobilização pedogenética. As análises DRX mostram a mesma composição do horizonte inferior, ou seja, caulinita, mica, quartzo, goethita e hematita.
No horizonte B (NL2), a foliação não é mais evidenciada, sendo o fundo matricial caracterizado por um esqueleto constituído por uma intensa disseminação das palhetas de mica dos fragmentos de xisto, em associação com fragmentos irregulares micrométricos de quartzo $(50$ a $200 \mu \mathrm{m})$. Esse esqueleto encontra-se disseminado em um plasma argiloferruginoso silassépico de composição caulinítica, ilítica, gibbsítica, goethítica e hematítica, definindo uma estrutura porfirogrânica (Figura 2f). Observase ainda um sistema de poros com vazios intra e transagregados. A intensificação da porosidade para o topo, com a presença de matéria orgânica nos vazios, marca a transição para o horizonte $\mathrm{A}$, que conserva ainda as mesmas características mineralógicas e texturais do horizonte B, caracterizando uma evolução in situ.

O horizonte A (NL1) é semelhante ao horizonte B, porém nele se observa intensificação dos poros e presença de restos orgânicos.

Perfil 5: Gnaisse do Embasamento - Analogamente aos perfis anteriores, o perfil de solo formado sobre esta unidade (Quadro 2) é pouco desenvolvido, sendo também classificado como Cambissolo Háplico (Embrapa, 2006).

A rocha fresca na base do perfil é um gnaisse constituído por plagioclásios e K-feldspatos parcialmente ilitizados e caulinizados, quartzo, biotita parcialmente cloritizada com algumas inclusões de zircão e epidoto.

No horizonte $\mathrm{C}$, saprolito (amostra E3), observa-se intensificação do processo de ilitização dos feldspatos, que culmina com a disseminação das palhetas de ilita em um plasma marrom-avermelhado (luz plana) com impregnação ferruginosa e na separação dos grãos residuais, como quartzo, feldspatos e traços de biotita.

Os cristais remanescentes de feldspato apresentam fortes reentrâncias e poros de dissolução, preferencialmente orientados segundo os planos de macla. Os cristais de biotita, parcialmente pseudomorfizados em clorita e caulinita, apresentam cor de polarização anormal, com tonalidade amarelada e planos de clivagem amarronzados, devido à exsudação do ferro. Os cristais de quartzo apresentam tamanhos e formas variadas $(<400 \mu \mathrm{m})$ e as bordas com reentrâncias de dissolução. Entretanto, localmente ocorrem porções relíquas da rocha fresca, onde os contatos entre os minerais encontram-se bem preservados. Tratase de porções ricas em quartzo e pobres em biotita.

No horizonte B (E2), o processo de ilitização e caulinização torna-se mais intenso, em associação com a exsudação do ferro, de modo a gerar uma textura porfirogrânica cujos constituintes do esqueleto são os mesmos do horizonte precedente, porém com tamanhos menores $(<300 \mu \mathrm{m})$ e feições de dissolução mais intensas. O plasma apresenta composição predominante de caulinita e, secundariamente, com 
ilita e goethita. A porosidade é incipiente, apresentando poros interagregados irregulares com ausência de cutãs. Localmente, observam-se vestígios de matéria orgânica.

No horizonte A (E1) ocorre intensificação do plasma, diminuição em intensidade e tamanho $(<100 \mu \mathrm{m})$ dos grãos do esqueleto, incremento nas feições de dissolução e aumento na porosidade, com poros inter e transagregados.

Perfil 6: Metadiabásio - Diferentemente dos perfis anteriores, o perfil de solo formado sobre esta unidade (Quadro 2) é mais desenvolvido, com horizonte B mais espesso $(\sim 1 \mathrm{~m})$, porém com porções de relíquias do saprolito em associação com minerais primários suscetíveis à alteração. Essas características contribuíram para a classificação deste perfil de solo como Latossolo Vermelho Aluminoférrico Cambissólico (Embrapa, 2006).

O horizonte C (D4) é caracterizado por um esqueleto formado por restos de feldspatos em diferentes estádios de alteração para caulinita, em contato difuso com um plasma argiloferruginoso de coloração castanho-amarelada (luz plana), constituído de caulinita, goethita, hematita e gibbsita. Como constituinte desse fundo matricial ocorrem ainda quartzo, de forma e tamanho variados (20-200 $\mu \mathrm{m})$, ilmenita e nódulos ferruginosos pedogenéticos e litorrelíquias. Os nódulos pedogenéticos são maciços, de cor marrom-acastanhada e se encontram em associação com as litorrelíquias formadas por feldspatos caulinizados e agrupamentos de quartzo policristalino, ocorrendo sob a forma lenticular, sugerindo uma ligeira foliação (Figura 2g).

Em amostras de rocha fresca de diabásio do Complexo do Bonfim (Carneiro et al., 1998) foram identificados principalmente plagioclásio $(47,9 \%)$, ortoclásio (11,5\%), quartzo (11,6 \%), ilmenita (4,4\%) e apatita $(1,4 \%)$, o que mostra uma analogia com os constituintes descritos no horizonte $\mathrm{C}$.

No horizonte B (amostra D3) observa-se dispersão dos grãos de quartzo, sendo o fundo matricial representado por um esqueleto predominantemente quartzoso, cujas características texturais e ópticas são análogas às dos grãos do horizonte precedente. Associado a esse fundo matricial têm-se nódulos litorreliquiais, análogos ao horizonte precedente, porém os feldspatos ocorrem totalmente caulinizados e ferruginizados (Figura 2h). Todos esses constituintes encontram-se em contato difuso com um plasma silassépico castanho-avermelhado composto de: caulinita, gibbsita, goethita e hematita. No topo do horizonte B (D2), as feições são semelhantes às observadas na base, mas as porções relíquas são de menor tamanho $(<200 \mu \mathrm{m})$ e com contato mais difuso com o plasma, atestando uma evolução in situ. Adicionalmente, observa-se um sistema de poros com fissuras irregulares, vazias, contínuas e descontínuas, evidenciando a ação pedogenética e a transição para o horizonte A.
No horizonte A (D1) ocorre um incremento substancial da porosidade, formado por fissuras irregulares inter, intra e transagregados.

Perfil 7: Itabirito da Formação Cauê - Os perfis de solos desenvolvidos sobre os itabiritos (BIF-Banded Iron Formations) são particulares, em virtude da composição química e mineralógica dessas rochas. $\mathrm{Na}$ sua grande maioria são pouco desenvolvidos, sendo classificados como Neossolos Litólicos e Neossolos Regolíticos (Embrapa, 2006). Quando um pouco mais evoluídos, devido à presença de níveis metapelíticos com anfibólio, podem chegar a Cambissolos.

Essas formações ferríferas são constituídas por bandas ricas em quartzo, alternadas com bandas ricas em óxidos de ferro, hematita (principalmente) e magnetita (subordinadamente). As bandas possuem espessura variável (milimétricas a métricas). Além do caráter bandado, essas rochas podem apresentar aspecto xistoso nas bandas ricas em hematita, devido ao habitus tabular e respectiva orientação preferencial deste mineral. No Quadrilátero Ferrífero ocorre ainda um tipo particular de BIF, pobre em sílica $(<5 \%)$, conhecido como hematita compacta (hard hematite, Dorr, 1965). Trata-se de corpos lenticulares constituídos predominantemente por hematita e, subordinadamente, por magnetita, parcial ou totalmente martitizada (Varajão et al., 1997).

A alteração supergênica isalterítica dessas rochas é marcada por uma dissolução congruente (Varajão et al., 1996a,b, 2000b). Os grãos de quartzo sofrem lento processo de corrosão por dissolução centrípeta e lixiviação da sílica (Figura 3), provocando uma fragilização da estrutura da rocha, tornando-a friável e, portanto, facilmente erodível. As hematitas são mais resistentes à dissolução, e apenas uma pequena parte do ferro é lixiviada. A maior parte permanece no perfil, formando plasmas hematíticos e, ou, goethíticos, que preenchem fissuras e cavidades geradas pela alteração supergênica dos constituintes da rocha. As magnetitas, por sua vez, podem ser totalmente martitizadas, sendo facilmente reconhecidas por preservarem o habitus octaédrico original da magnetita. Quando parcialmente martitizadas, podem apresentar núcleos de maghemita ou kenomagnetita, os quais são mais suscetíveis ao processo de dissolução supergênica, gerando cavidades (Figura 2i), que, juntamente com as fissuras, são as principais responsáveis pela microporosidade (Varajão et al., 2002) do horizonte C. Assim, o ferro originado da dissolução dos óxidos primários passa por inúmeras etapas de dissolução/reprecipitação, que progressivamente tendem a apagar a textura inicial do itabirito, gerando um horizonte incipiente, no qual podem-se reconhecer fragmentos da rocha-mãe, conhecido como canga (horizonte C/B). Quando, numa canga, a estrutura da rocha é macroscopicamente reconhecível, usa-se a denominação canga estruturada, tratando-se, portanto, de um horizonte C. As cangas, embora mecanicamente resistentes, 


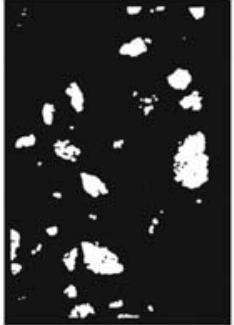

A $-0,5 \mathrm{~m}$

D - $8 \mathrm{~m}$

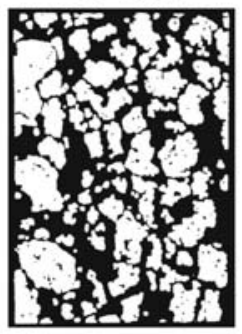

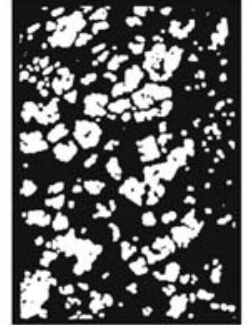

B - 2,5 m

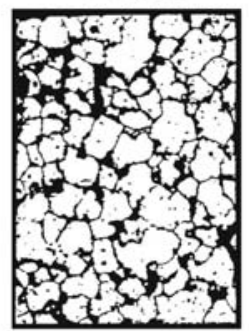

E - $149 \mathrm{~m}$

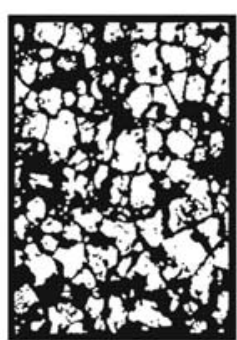

C $-5 \mathrm{~m}$

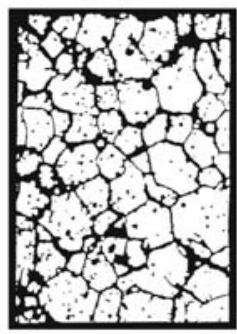

F - $195 \mathrm{~m}$
Figura 3. Imagens digitalizadas de lâminas delgadas em níveis quartzosos de itabirito, de amostras coletadas a diferentes profundidades, mostrando a dissolução dos grãos de quartzo $(1 \mathrm{~cm}=75 \mu \mathrm{m})$.

podem ser destruídas na base, devido a eventuais oscilações do lençol freático, ou no topo, pela ação dos agentes intempéricos biogênicos, gerando um horizonte superficial A, pouco espesso, centimétrico, constituído de pequenas partículas ferruginosas, que guardam, internamente, as mesmas características texturais, químicas e mineralógicas da canga que foi desagregada.

Devido à resistência mecânica das cangas e à vizinhança estratigráfica com os quartzitos (Grupo Caraça), os itabiritos ocupam sempre uma posição de destaque na paisagem e constituem cristas das serras da região, cujo aspecto grosseiramente quadrangular é o responsável pela designação Quadrilátero Ferrífero.

Perfil 8: Quartzito do Grupo Caraça - Similarmente aos itabiritos, os perfis de solos desenvolvidos sobre os quartzitos, devido à composição mineralógica desta rocha, ou seja, com mais de $80 \%$ de quartzo, são pouco evoluídos, sendo classificados como Neossolos Litólicos. Particularmente, quando da presença de níveis micáceos na rocha-mãe, caracterizando-a como um quartzo-mica-xisto, tem-se a formação de um horizonte C (Quadro 2, amostra Q3) mais desenvolvido ou mesmo a formação de um horizonte B (Quadro 2, amostra Q2) incipiente, sendo classificados, respectivamente, como Neossolos Regolíticos ou Cambissolos.

\section{Análises químicas dos perfís de solos e das águas}

O comportamento dos elementos maiores nos perfis de alteração, desde as amostras de rocha fresca, sua distribuição nos horizontes de solo até suas concentrações nas águas (Salgado et al., 2004) que drenam esses horizontes, coletadas nos períodos úmido (verão) e seco (inverno), é apresentado no quadro 3.

De maneira geral, observa-se uma tendência de enriquecimento relativo dos elementos $\mathrm{Fe}, \mathrm{Al}$ e $\mathrm{Mn}$ e um empobrecimento em $\mathrm{K}$ ao longo dos perfis de alteração. Para os elementos $\mathrm{Na}, \mathrm{Ca}$ e $\mathrm{Mg}$, a distribuição é irregular, não existindo uma tendência linear. Essa irregularidade reflete as variações mineralógicas dos diferentes litotipos, assim como a baixa maturidade dos perfis de alteração, evidenciados pelos estudos micromorfológicos. No caso particular do $\mathrm{Si}$, os teores elevados nos horizontes A (xisto Sabará, filito Fecho do Funil e gnaisse) evidenciam uma importante concentração relativa de quartzo no topo desses perfis.

Em concordância com o observado nos perfis de alteração, $\mathrm{Fe}, \mathrm{Al}$ e $\mathrm{Mn}$ apresentam baixas concentrações nas águas. $\mathrm{Na}, \mathrm{Ca}$ e $\mathrm{Mg}$, apesar de apresentarem teores irregulares nos perfis de alteração, mostram sempre altas concentrações nas águas, o que atesta a alta mobilidade destes elementos. Por outro lado, as baixas concentrações em $\mathrm{K}$ nas águas podem ser explicadas pela presença constante de mica e ilita particularmente nos horizontes C e B. Cabe ressaltar ainda que o Si apresenta sempre fortes concentrações nas águas, particularmente nos xistos e gnaisses.

\section{DISCUSSÃO}

As taxas de erosão obtidas por meio do método ${ }^{10} \mathrm{Be}$ revelaram para o Quadrilátero Ferrífero um valor médio da ordem de $7 \mathrm{~m} \mathrm{Ma}^{-1}$. Esse resultado, quando comparado com o de outras partes do Brasil (Quadro 4), revela dissonância com os resultados de Cuiabá e similaridade com os do Estado da Bahia e do Distrito Federal. Essas áreas encontram-se separadas por um lineamento N45E, que corta o território brasileiro do noroeste do Ceará ao sudoeste do Mato Grosso, denominado por Schobenhaus (1975) como Lineamento Transbrasiliano (LB). Segundo Neves (1991), esse lineamento divide o País em dois domínios geotectônicos: os "Dois Brasis" ou "Dois Brasis Geomorfológicos" (Saadi, 1993).

A Plataforma Sul-americana, no seu conjunto, encontra-se em processo de soerguimento (Saadi, 1993; Ricomini \& Assumpção, 1999). Para Saadi et al. (2005), como resposta aos movimentos tectônicos epirogenéticos, o soerguimento do Brasil Oriental teria ocorrido em pulsos, provocando a reativação de lineamentos e geossuturas nos períodos EocenoOligoceno, Mioceno, Plioceno e Pleistoceno de, respectivamente, 35-33, 16-13, 7 e 1 Ma. O período Eoceno, na região Sudeste, foi marcado por um soerguimento epirogenético concomitante a uma fase tectônica distensiva, com formação de estruturas "horst/graben" e consequente formação de bacias. Têm-se como exemplo as bacias de Taubaté, Resende e, particularmente no Quadrilátero Ferrífero, as bacias de Gandarela e Fonseca (Gorceix, 1884; Maxwell, 
Quadro 3. Análises químicas totais dos perfis de solo estudados neste trabalho e das águas nos períodos verão úmido (U) e inverno seco (S), segundo Salgado et al. (2004)

\begin{tabular}{|c|c|c|c|c|c|c|c|c|c|}
\hline & & $\mathbf{C a}$ & $\mathrm{Na}$ & $\mathbf{K}$ & $\mathrm{Fe}$ & Mg & Al & Mn & $\mathrm{Si}$ \\
\hline Perfil 1 - Xisto & $\mathrm{U} m \mathrm{~g} \mathrm{~L}^{-1}$ & 4.325 & 0.239 & 0.104 & 0.018 & 2.756 & 0.007 & 0.013 & 1.66 \\
\hline G. Sabará & $\mathrm{S} \mathrm{mg} \mathrm{L}^{-1}$ & 6.31 & 0.169 & 0.125 & 0.010 & 3.683 & 0.001 & 0.012 & 2.035 \\
\hline HA - S1 & $\mathrm{mg} \mathrm{kg}^{-1}$ & 72.0 & 2.418 & 16.845 & 251.912 & 41.775 & 97.233 & 3.541 & 16.500 .466 \\
\hline $\mathrm{HC}-\mathrm{S} 2$ & $\mathrm{mg} \mathrm{kg}^{-1}$ & 38.5 & 6.344 & 45.845 & 94.046 & 15.596 & 155.475 & 277 & 1.289 .376 \\
\hline $\mathrm{HC}-\mathrm{S} 3$ & $\mathrm{mg} \mathrm{kg}^{-1}$ & 19.6 & 5.124 & 37.769 & 94.419 & 15.658 & 166.860 & 196 & 91.3327 \\
\hline $\mathrm{HC}-\mathrm{S} 4$ & $\mathrm{mg} \mathrm{kg}^{-1}$ & 22.3 & 4.695 & 33.932 & 80.540 & 13.356 & 128.016 & 135 & 62.6747 \\
\hline \multicolumn{10}{|l|}{$\mathrm{R}$} \\
\hline \multicolumn{10}{|c|}{ Perfil 2 - Filito F. Batatal } \\
\hline $\mathrm{HB}-\mathrm{B} 1$ & $\mathrm{mg} \mathrm{kg}^{-1}$ & 31.3 & 280 & 75.626 & 25.947 & 8261 & 204.297 & 18 & 188.723 \\
\hline $\mathrm{HC}-\mathrm{B} 2$ & $m g \mathrm{~kg}^{-1}$ & 37.2 & 303 & 85.505 & 14.057 & 9769 & 214.036 & 15 & 204.100 \\
\hline $\mathrm{HC}-\mathrm{B} 3$ & $\mathrm{mg} \mathrm{kg}^{-1}$ & 33.4 & 969 & 76.528 & 11.401 & 6639 & 157.442 & 7.79 & 246.350 \\
\hline $\mathrm{R}$ & $\mathrm{mg} \mathrm{kg}^{-1}$ & 45.1 & 204 & 32.680 & 45.782 & 6883 & 53.873 & 59.50 & 291.393 \\
\hline Perfil 3 - Filito & $\mathrm{U} \mathrm{mg} \mathrm{L}^{-1}$ & 6.64 & 0.375 & 0.350 & 0.280 & 2.293 & 0.005 & 0.86 & 2.157 \\
\hline F. Fecho do Funil & $\mathrm{S} \mathrm{mg} \mathrm{L}^{-1}$ & 7.82 & 0.293 & 3.336 & 0.273 & 2.723 & 0.004 & 0.244 & 2.114 \\
\hline $\mathrm{HA}-\mathrm{F} 1$ & $\mathrm{mg} \mathrm{kg}^{-1}$ & 4.371 & 1.507 & 28.180 & 77.406 & 1111 & 114.599 & 666 & 3103.448 \\
\hline $\mathrm{HC}-\mathrm{F} 2$ & $\mathrm{mg} \mathrm{kg}^{-1}$ & 13.377 & 1.981 & 27.720 & 80.561 & 1007 & 118.766 & 163 & 760.485 \\
\hline $\mathrm{HC}-\mathrm{F} 3$ & $\mathrm{mg} \mathrm{kg}^{-1}$ & 8.761 & 2.078 & 37.665 & 75.989 & 1264 & 114.599 & 711 & 331.314 \\
\hline $\mathrm{R}$ & $\mathrm{mg} \mathrm{kg}^{-1}$ & 1.571 & 3.041 & 61.922 & 156.886 & 1863 & 138.629 & 198 & 922.181 \\
\hline Perfil 4 - Xisto & $\mathrm{U} \mathrm{mg} \mathrm{L}^{-1}$ & 0.163 & 0.197 & 0.152 & 0.024 & 1.572 & $<0.001$ & 0.006 & 0.797 \\
\hline G. Nova Lima & $\mathrm{S} \mathrm{mg} \mathrm{L}^{-1}$ & 1.292 & 0.365 & 0.103 & 0.144 & 1.648 & $<0.001$ & 0.006 & 3.895 \\
\hline HA - NL1 & $\mathrm{mg} \mathrm{kg}^{-1}$ & 124.2 & 196 & 4.600 & 169.199 & 564 & 109.467 & 772 & 174.109 \\
\hline HB - NL2 & $\mathrm{mg} \mathrm{kg}^{-1}$ & $<10,0$ & 275 & 6.347 & 158.630 & 689 & 123.412 & 350 & 187.896 \\
\hline $\mathrm{HB} / \mathrm{C}$ - NL3 & $\mathrm{mg} \mathrm{kg}^{-1}$ & $<10,0$ & 205 & 4.900 & 158.454 & 657 & 116.824 & 328 & 196.690 \\
\hline HC - NL4 & $\mathrm{mg} \mathrm{kg}^{-1}$ & 39.7 & 224 & 5.427 & 142.507 & 564 & 113.956 & 564 & 214.658 \\
\hline $\mathrm{R}$ & $\mathrm{mg} \mathrm{kg-1}$ & 5.512 & $<3,27$ & $<6,70$ & 217.497 & 15811 & 63.121 & 653 & 3042.870 \\
\hline Perfil 5-Gnaisse & $\mathrm{U} \mathrm{mg} \mathrm{L}^{-1}$ & 1.599 & 2.168 & 1.05 & 1.222 & 0.711 & 0.023 & 0.489 & 5.26 \\
\hline Embasamento & $\mathrm{S} \mathrm{mg} \mathrm{L}^{-1}$ & 1.028 & 2.718 & 1.186 & 0.474 & 0.409 & 0.016 & 0.263 & 6.36 \\
\hline HA - E1 & $\mathrm{mg} \mathrm{kg}^{-1}$ & 451 & 1.113 & 14.784 & 43.297 & 1400 & 94.709 & 132 & 612.768 \\
\hline HB - E2 & $\mathrm{mg} \mathrm{kg}^{-1}$ & 289 & 991 & 17.428 & 17.675 & 1815 & 112.125 & 103 & 479.031 \\
\hline $\mathrm{HC}-\mathrm{E} 3$ & $\mathrm{mg} \mathrm{kg}^{-1}$ & 59.1 & 553 & 17.718 & 11.783 & 985 & 106.889 & 63.2 & 294.501 \\
\hline $\mathrm{R}$ & $\mathrm{mg} \mathrm{kg}^{-1}$ & 17.245 & 37.546 & 15.579 & 15.597 & 3646 & 83.865 & 256 & 385.512 \\
\hline \multicolumn{10}{|c|}{ Perfil-6 Metadiabásio } \\
\hline HA - D1 & $\mathrm{mg} \mathrm{kg}^{-1}$ & 179 & 60.1 & 479 & 120.498 & 389 & 85.162 & 210 & 64.966 \\
\hline $\mathrm{HB}-\mathrm{D} 2$ & $\mathrm{mg} \mathrm{kg}^{-1}$ & 32.8 & 61.1 & 1.167 & 184.638 & 692 & 160.376 & 270 & 106.636 \\
\hline HB - D3 & $\mathrm{mg} \mathrm{kg}^{-1}$ & 9.69 & 53.7 & 1.287 & 200.389 & 552 & 146.723 & 379 & 123.657 \\
\hline $\mathrm{HC}-\mathrm{D} 4$ & $\mathrm{mg} \mathrm{kg}^{-1}$ & $<10,0$ & $<3,27$ & 34.58 & 233.883 & 30.1 & 129.215 & 226 & 128.695 \\
\hline $\mathrm{R}$ & $\mathrm{mg} \mathrm{kg}^{-1}$ & 35.734 & 28.189 & 15.772 & 41.264 & 12663 & 72.509 & 1394 & 261.882 \\
\hline \multicolumn{10}{|c|}{ Perfil 7 - Itabirito F. Cauê } \\
\hline HC IT1 & $\mathrm{mg} \mathrm{kg}^{-1}$ & 16.9 & $<3,27$ & $<6,70$ & 615.762 & $<0,17$ & 3.942 & 662 & 23.057 \\
\hline $\mathrm{R}$ & $\mathrm{mg} \mathrm{kg}^{-1}$ & 32.9 & $<3,27$ & 22.96 & 621.087 & $<0,17$ & 11.129 & 731 & 14.895 \\
\hline HC IT2 & $\mathrm{mg} \mathrm{kg}^{-1}$ & 21.7 & $<3,27$ & $<6,70$ & 584.457 & $<0,17$ & 842 & 617 & 74.979 \\
\hline $\mathrm{R}$ & $\mathrm{mg} \mathrm{kg}{ }^{-1}$ & 27.6 & $<3,27$ & $<6,70$ & 573.750 & $<0,17$ & 452 & 557 & 82.569 \\
\hline Perfil 8-Quartzito & $\mathrm{U} \mathrm{mg} \mathrm{L}^{-1}$ & 0.135 & $<0.055$ & $<0.001$ & 0.102 & 0.117 & 0.044 & $*<\mathrm{DL}$ & 1.247 \\
\hline G. Caraça & $\mathrm{S} \mathrm{mg} \mathrm{L}^{-1}$ & 0.115 & $<0.055$ & 0.061 & 0.074 & 0.074 & 0.028 & $*<\mathrm{DL}$ & 1.723 \\
\hline $\mathrm{R}$ & $\mathrm{mg} \mathrm{kg}^{-1}$ & 0.001 & 75.8 & 3.491 & 4.313 & 643 & 8.653 & 21.7 & 450.310 \\
\hline
\end{tabular}

1972). Lipski (2002) efetuou análises de paleotensões em sedimentos terciários do Quadrilátero Ferrífero e identificou três eventos neotectônicos: (1) no Oligoceno, relacionado à geração de grabens, igualmente ao descrito por Maizatto (2001) para o fechamento das bacias Gandarela e Fonseca; e (2) e (3) no Plioceno, relacionados à reativação das estruturas preexistentes nas encaixantes.
Nesse contexto tectônico, as taxas de erosão obtidas pelo método ${ }^{10}$ Be na Bahia, Brasília e Quadrilátero Ferrífero são similares, por se encontrarem na porção $\mathrm{E}$ do LB, área que foi submetida a pulsos neotectônicos de soerguimento e aos consequentes processos erosivos. Por outro lado, à $\mathrm{W}$ do $\mathrm{LB}$, à exceção da área de subsidência do Pantanal Mato-grossense, a plataforma se manteve estável. Assim, a taxa de erosão em 


\section{Quadro 4. Taxas de erosão medidas pelo método ${ }^{10} \mathrm{Be}$ em outras regiões do Brasil e do mundo}

\begin{tabular}{|c|c|c|c|c|}
\hline Local & Tectônica & Solos e rochas & Taxa & Autores \\
\hline \multicolumn{5}{|c|}{$\mathrm{m} \mathrm{Ma}^{-1}$} \\
\hline Brasil (Itaberaba/BA) & Cráton & Antiga laterita & 9,0 & Braucher et al., 1998a \\
\hline Brasil (Gentio do Ouro/BA) & Cráton & Quartzitos & 2,5 & Braucher et al., 1998a \\
\hline Brasil (Cuiabá/MT) & Cráton & Crostas ferrug. desmanteladas & 0,5 & Braucher et al., 1998a \\
\hline Brasil (Brasília/ DF) & & Latossolo & 4,5 & Braucher et al., 2004 \\
\hline Sudoeste de Burkina Faso & Estável & Crosta Laterítica & 1,5 & Braucher et al., $1998 \mathrm{~b}$ \\
\hline Sudoeste do Congo (Brazville) & Estável & Latossolo & 12,0 & Braucher et al., $1998 \mathrm{~b}$ \\
\hline Camarões & & Latossolo & $0,7-1,2$ & Braucher et al., 2000 \\
\hline Gabão & & Latossolo & 2,0 & Braucher et al., 2000 \\
\hline Antártica & Não informado & Granito-gnaisse & 10,0 & Matsuoka et al., 2006 \\
\hline Himalaia & Ativa & - & 42,0 & Heimsath \& McGlynn, 2008 \\
\hline Japão & Ativa & Arenitos, argilitos, conglomerados & 90,0 & Matsushi et al., 2006 \\
\hline
\end{tabular}

Cuiabá é mais baixa, porém similar às taxas de erosão medidas na África do oeste, onde, igualmente, os terrenos se encontram em regime de plataforma estável. O quadro 4 revela os altos valores de taxas de erosão para as áreas tectonicamente ativas do mundo (Antártica, Japão e Himalaia).

As coberturas lateríticas do Quadrilátero Ferrífero constituem igualmente registro e fonte de informações para a datação direta ou indireta das variações climáticas, assim como da tectônica recente na região. Um exemplo é o platô de $900 \mathrm{~m}$ de altitude (Chapada do Canga), localizado no sopé SE da Serra do Caraça, que exibe expressiva cobertura laterítica (canga e bauxita) formada a partir dos sedimentos terciários da Formação Fonseca (Gorceix, 1884; Maxwell, 1972), cujas datações (Maizatto, 2001) revelaram idades concordantes com a tectônica distensiva formadora dos riftes na região Sudeste do Brasil (Ricomini et al., 1983). Posteriormente, com o soerguimento da Plataforma Sul-americana durante o Mioceno, sob condições de clima úmido e quente (Maizatto, 2001), ocorreu a laterização desses sedimentos terciários, com a formação de cangas e bauxitas, colocando-as como as mais jovens do Quadrilátero Ferrífero. As mais antigas seriam de idade eocênica (Spier et al., 2006), em concordância com a maioria dos depósitos das diferentes regiões do planeta (Tardy et al., 1991). Assim, as superfícies cimeiras interpretadas por diferentes autores como cretácicas são protegidas contra a erosão mecânica por coberturas de canga formadas, principalmente, durante o Eoceno.

Os perfis de solos descritos neste trabalho e que foram desenvolvidos sobre os diferentes litotipos mostram características de autoctonia. Como observado nos estudos micromorfológicos, as descontinuidades texturais e por vezes mineralógicas são decorrentes de variações faciológicas na rocha-mãe. Independentemente do tipo litológico a que são filiados, são perfis pouco desenvolvidos, com horizonte B ausente ou incipiente, sendo classificados como Neossolos e Cambissolos, exceto o perfil 6, atestando, desse modo, uma importante atividade erosiva. Entretanto, deve-se ressaltar, como relatado no item Quadrilátero Ferrífero, a ocorrência de solos bem desenvolvidos, com horizonte B latossólico sobre os litotipos: gnaisse do Complexo do Bação (CETEC, 1983; Parsanese, 2001), itabiritos do Grupo Itabira (Camargo, 1982; Costa, 2003) e xistos do Grupo Nova Lima (CETEC-FEAM-UFV). Contudo, geneticamente, estes não foram desenvolvidos a partir do substrato local, e sim sobre materiais coluvionares oriundos de perfis lateríticos formados in situ, mais a montante, a partir desses mesmos substratos rochosos.

A presença concomitante de perfis autóctones pouco desenvolvidos e perfis alóctones bem desenvolvidos, relacionados ao mesmo substrato rochoso, constitui uma importante informação da história recente, controlada pela neotectônica, que levou ao desencadeamento de um intenso processo erosivo no Quadrilátero Ferrífero. Esse processo erosivo de perfis lateríticos, formados no Eoceno e Mioceno, teria acontecido graças a uma conjunção de fatores ocorridos no Plioceno: o clima árido dominante e os pulsos tectônicos (7 e $1 \mathrm{Ma}$ ), formando depósitos alóctones, posteriormente pedogenizados; como, por exemplo, no Complexo Bação (Bacellar et al., 2005), onde foram datadas argilas orgânicas holocênicas (33 e 7 Ma).

Os dados geoquímicos dos perfis de solos mostram variações dos elementos em função dos tipos litológicos envolvidos, da heterogeneidade de suas composições mineralógicas e da suscetibilidade dos diferentes minerais à alteração. As águas que drenam xistos e gnaisses apresentam teores mais elevados de $\mathrm{Si}, \mathrm{Na}$ e Fe (Quadro 3) do que as águas que drenam quartzitos e itabiritos (Quadro 5). Ou seja, essas águas possuem teores em Fe maiores que as provenientes de itabiritos e, analogamente, teores maiores de $\mathrm{Si}$ que aquelas provenientes de quartzitos.

A concordância entre os dados geoquímicos pedológicos e os dados hidroquímicos evidencia, desse modo, a importância da análise integrada da 
Quadro 5. Análises químicas em aquíferos de diferentes litotipos do Quadrilátero Ferrífero segundo: (1) Mendes (2007) e (2) Mourão (2007)

\begin{tabular}{|c|c|c|c|c|c|c|c|c|c|}
\hline & & $\mathbf{C a}$ & $\mathbf{N a}$ & $\mathbf{K}$ & $\mathbf{F e}$ & Mg & Al & Mn & $\mathrm{Si}$ \\
\hline Grupo Caraça (1) & $\mathrm{mg} \mathrm{L}^{-1}$ & 9,98 & 0,56 & 0,4 & 0,13 & 0,6 & 0,071 & 0,08 & nd \\
\hline Form. Cauê (2) & $\mathrm{mg} \mathrm{L}^{-1}$ & 1,65 & 0,32 & 0,2 & 0,16 & 0,87 & 0,08 & 0,02 & 2,89 \\
\hline Form. Gandarela (2) & $\mathrm{mg} \mathrm{L}^{-1}$ & 12,63 & 0,37 & 0,27 & 0,56 & 6,68 & 0,12 & 0,05 & 3,55 \\
\hline Grupo Caraça (2) & $\mathrm{mg} \mathrm{L}^{-1}$ & 8,6 & 0,43 & 0,42 & 0,32 & 4,61 & $<\mathrm{LQ}$ & 0,76 & 3,29 \\
\hline Embasamento (2) & $\mathrm{mg} \mathrm{L}^{-1}$ & 5,53 & 2,88 & 1 & 1,19 & 2,37 & 0,26 & 0,13 & 5,84 \\
\hline Grupo Nova Lima (2) & $\mathrm{mg} \mathrm{L}^{-1}$ & 9,62 & 1,47 & 0,41 & 1,06 & 6,45 & 0,21 & 0,13 & 5,1 \\
\hline
\end{tabular}

pedogênese com as análises químicas dos solos e das águas na compreensão da evolução da paisagem.

\section{CONCLUSÕES}

1. A análise integrada dos estudos mineralógicos, micromorfológicos e químicos dos perfis de solos desenvolvidos a partir dos principais litotipos da região em diferentes bacias, confrontados com a análise química das nascentes e as taxas de erosão $\left({ }^{10} \mathrm{Be}\right)$, permite a compreensão quantitativa do papel do intemperismo e da erosão na evolução da paisagem do Quadrilátero Ferrífero.

2. A análise das transformações pedológicas revelou que, independentemente do tipo litológico, os solos autóctones são predominantemente imaturos (Neossolos e Cambissolos). Esse fato sugere que o relevo da região é produto de um processo erosivo intenso e constante.

3. O valor da taxa de erosão média de $7 \mathrm{~m} \mathrm{Ma}^{-1}$ $\left({ }^{10} \mathrm{Be}\right)$ atesta igualmente um importante soerguimento epirogenético, em concordância com as evidências da tectônica recente da região.

4. Os dados pedogenéticos, hidroquímicos e as taxas de erosão $\left({ }^{10} \mathrm{Be}\right)$ apresentados neste trabalho concordam com os dados paleontológicos e geocronológicos do Quadrilátero Ferrífero, constituindo assim uma importante ferramenta para a compreensão e quantificação dos processos geomorfológicos, bem como da evolução da paisagem da região.

\section{AGRADECIMENTOS}

Ao IRD (Institute de Recherche pour le Développement, France), pela bolsa BESCD atribuída a César A.C.Varajão, e à CAPES, FAPEMIG e CNPq, pelo apoio financeiro.

\section{LITERATURA CITADA}

ALKMIM, F.F. \& MARSHAK, S. Transamazonian Orogeny in the Southern São Francisco Craton Region, Minas Gerais Brazil: Evidence for a Paleoproterozoic collision and collapse in Quadrilátero Ferrífero. Precamb. Res., 90:29$58,1998$.

ALMEIDA, F.F.M. O Cráton do São Francisco. R. Bras. Geoci., $7: 349-364,1977$.

BACELLAR, L.A.P.; COELHO NETTO, A.L. \& LACERDA, W.A. Controlling factors of gulling in the Maracujá catchment, Southeastern Brazil. Earth Surf. Process. Landforms, 30:1369-1385, 2005.

BARBOSA, G.V. Superfícies de erosão no Quadrilátero Ferrífero. São Paulo. R. Bras. Geoci., 10:89-101, 1980.

BARBOSA, G.V. \& RODRIGUES, D.M.S. O Quadrilátero Ferrífero e seus problemas geomorfológicos. B. Min. Geogr., 10/11:3-35, 1965.

BLANCKENBURG, von F. The control mechanisms of erosion and weathering at basin scale from cosmogenic nuclides in river sediment. Earth Planet. Sci. Lett., 237:462-479, 2005.

BRAUCHER, R.; COLIN, F.; BROWN, E.T.; BOURLÈS, D.L.; BAMBA, O.; RAISBECK, G.M.; YIOU, F. \& KOUD, J.M. African laterite dynamics using in situ-produced $10 \mathrm{Be}$. Geochem. Cosmochem. Acta, 62:1501-1507, 1998a.

BRAUCHER, R.; BOURLES D.L.; COLIN, F.; BROWN, E.T. \& BOULANGÉ, B. Brazilian laterite dynamics using in situproduced 10Be. Earth Planet. Sci. Lett., 163:197-205, $1998 \mathrm{~b}$.

BRAUCHER, R.; BOURLÈS, D.L.; BROWN, E.T.; COLIN, F.; MULLER, J.P.; BRAUN, J.J.; DELAUNE, M.; EDOUMINKO, A.; LESCOUET, C.; RAISBECK, G.M. \& YIOU, F. Application of in situ-produced cosmogenic $10 \mathrm{Be}$ and $26 \mathrm{Al}$ to the study of lateritic soil development in tropical forest: Theory and examples from Cameroon and Gabon. Chem. Geol., 170:95-111, 2000.

BRAUCHER, R.; BROWN, E.T.; BOURLÈS, D.L. \& COLIN, F. In situ produced $10 \mathrm{Be}$ measurements at great depths: Implications for production rates by fast muons. Earth Planet. Sci. Lett., 211:251-258, 2003. 
BRAUCHER, R.; LIMA, C.V.; BOURLÈS, D.L.; GASPAR, J.C. \& ASSAD, M.L.L. Stone-line formation processes documented by in situ-produced 10Be distribution, Jardim River basin, DF, Brazil. Earth Planet. Sci. Lett., 222:645$651,2004$.

BREWER, R. Fabric and mineral analysis of soils. New York, John Wiley \& Sons, 1976. 481p.

BROWN, E.T.; COLIN, F. \& BOURLÈS, D.L. Quantitative evaluation of soil processes using in situ-produced cosmogenic nuclides. C. R. Geosci., 335:1161-1171, 2003.

BROWN, E.T.; STALLARD, R.F.; LARSEN, M.C.; RAISBECK, G.M. \& YIOU, F. Denudated rates determined from accumulation of in situ produced ${ }^{10} \mathrm{Be}$ in the Luquillo Experimental Forest, Puerto Rico. Earth Planet. Sci. Lett., 129:193-202, 1995.

CAMARGO, M.N. Proposição preliminar de conceituação de Latossolos ferríferos. In: EMPRESA BRASILEIRA DE PESQUISA AGROPECUÁRIA - EMBRAPA. Serviço Nacional de Levantamento e Conservação de Solos. Conceituação sumária de algumas classes de solos recémreconhecidas nos levantamentos e estudos de correlação do SNLCS. Rio de Janeiro, 1982. p.29-31. (Circular Técnica, 1)

CARNEIRO, M.A.; CARVALHO, JÚNIOR, I.M. \& TEIXEIRA, W. Petrologia, geoquímica e geocronologia dos diques máficos do Complexo Metamórfico Bonfim Setentrional (Quadrilátero Ferrífero) e suas implicações na evolução crustal do Craton São Francisco Meridional. R. Bras. Geoci., 28:29-44, 1998.

COSTA, S.A.D. Caracterização química, física, mineralógica e classificação de solos ricos em ferro do Quadrilátero Ferrífero. Viçosa, MG, Universidade Federal de Viçosa, 2003. 71p. (Tese de Mestrado)

DORR, J.V.N. Nature and origin of the high grade hematite ores of Minas Gerais Brazil Econ. Geol., 60:1-46, 1965.

DORR, J.V.N. Physiographic, stratigraphic and structural development of the Quadrilátero Ferrífero, Minas Gerais, Brazil. Porto Alegre, Universidade Federal do Rio Grande do Sul, 1969. 110p. (Professional Paper, 641A)

EMPRESA BRASILEIRA DE PESQUISA AGROPECUÁRIA EMBRAPA. Serviço Nacional de Levantamento e Conservação de Solos. Sistema brasileiro de classificação de solos. Rio de Janeiro, 2006. 306p.

FIGUEIREDO, M.A.; VARAJÃO, A.F.D.C.; FABRIS, J.D.; LOUTFI, I.S. \& CARVALHO, A.P. Alteração superficial e pedogeomorfologia no sul do Complexo Bação . Quadrilátero Ferrífero (MG). R. Bras. Ci. Solo, 28:713 $729,2004$.

FUNDAÇÃO CENTRO TECNOLÓGICO DE MINAS GERAIS - CETEC. Diagnóstico ambiental do Estado de Minas Gerais. Belo Horizonte, 1983. 158p.

GORCEIX, H. Bacia terciária de água doce nos arredores de Ouro Preto (Gandarela e Fonseca), Minas Gerais, Brasil. An. Escola Minas, 3:75-92, 1884.

GRANGER, D.E.; KIRCHNER, J.W. \& FINKEL, R. Spatially averaged long-term erosion rates measured from in situproduced cosmogenic nuclides in alluvial sediment. J. Geol., 104:249-257, 1996.
HADER, E.C. \& CHAMBERLIN, R.T. The geology of Central Minas Gerais. J. Geol., 23:341-424, 1915.

HEIMSATH, A.M. \& MCGLYNN, R. Quantifying periglacial erosion in the Nepal high Himalaya. Geomorphology, 97:5$23,2008$.

KING, L.C. A Geomorfologia do Brasil Oriental. R. Bras. Geoci., $18: 147-265,1956$

LIPSKI, M. Tectonismo Cenozóico no Quadrilátero Ferrífero, Minas Gerais. Ouro Preto, Universidade Federal de Ouro Preto, 2002. 171p. (Tese de Mestrado)

MAIZATTO, J.R. Análise bioestratigráfica, paleoecológica e sedimentológica das bacias terciárias de Fonseca e Gandarela - Quadrilátero Ferrífero - Minas Gerais, com base nos aspectos palinológicos e sedimentares. Ouro Preto, Universidade Federal de Ouro Preto, 2001. 249p. (Tese de Doutorado)

MATSUOKA, N.; THOMACHOT, C.E.; OGUCHI, C.T.; HATTA, T.; ABE, M. \& MATSUZAKI, H. Quaternary bedrock erosion and landscape evolution in the Sør Rondane Mountains, East Antarctica: Reevaluating rates and processes. Geomorphology, 81:408-420, 2006.

MATSUSHI, Y.; WAKASA, S.; MATSUZAKI, H. \& MATSUKURA, Y. Long-term denudation rates of actively uplifting hillcrests in the Boso Peninsula, Japan, estimated from depth profiling of in situ-produced cosmogenic 10Be and 26Al. Geomorphology, 82:283-294, 2006.

MAXWELL, C.H. Geology and ore deposits of the Alegria district, Minas Gerais, Brazil. Washington, U.S. Geol. Survey Prof. Paper, 1972. 72p. (341j)

MENDES, M.A.M. Influência antrópica nas características hidrossedimentológicas e geoquímicas da bacia do ribeirão Caraça, Quadrilátero Ferrífero. Ouro Preto, Universidade Federal de Ouro Preto, 2007. p.82. (Tese de Mestrado)

MOURÃO, M.A.A. Caracterização hidrogeológica do aquífero Cauê, Quadrilátero Ferrífero, MG. Belo Horizonte, Universidade Federal de Minas Gerais, 2007. 297p. (Tese de Doutorado)

NEVES, B.B.B. Os Dois "Brasis" geotectônicos. In: SIMPÓSIO DE GEOLOGIA DO NORDESTE, 15., Recife, 1991. p.6-8.

PARSANESE, G.A.C. Gênese e desenvolvimento de voçorocas em solos originados de rochas granitóides na região de Cachoeira do Campo, Minas Gerais. Viçosa,MG, Universidade Federal de Viçosa. 1991. 117p. (Tese de Mestrado)

PINET, P. \& SOURIAU, M. Continental erosion and largescale relief. Tectonics, 7:563-582, 1988.

REESMAN, A.L. \& GODFREY, A.E. Development of the Central Basin of Tennessee by chemical denudation. Z. Geomorph. N.F., 25:437-456, 1981.

RICCOMINI, C. \& ASSUMPÇÃO, M. Quaternary tectonics in Brazil. Episodes, 22:221-225, 1999. 
RICCOMINI, C.; MELO, M.S.; CARNEIRO,C.D.R.; ALMEIDA, F.F.M.; MIOTO, J.A. \& YOCITERU, H. Sobre a ocorrência de um derrame de ankaramito na Bacia de Volta Redonda (RJ) e sua importância na datação das bacias Geologia do Estado do Rio de Janeiro tafrogênicas continentais do sudeste brasileiro. In: SIMPÓSIO REGIONAL DE GEOLOGIA, 4., São Paulo, 1983. p.23-24.

SAADI, A. Neotectônica da Plataforma Brasileira: Esboço e interpretação preliminares. Geonomos, 1:1-15, 1993.

SAADI, A.; BEZERRA, F.H.R.; COSTA, R.D.; IGREJA, H.L.S. \& FRANZINELLI, E. Neotectônica da Plataforma Brasileira. In: SOUZA C.R.G.; SUGUIO, K.; OLIVEIRA A.M.S. \& OLIVEIRA, P.E., eds. Quaternário do Brasil. Ribeirão Preto, Holos, 2005. p.211-234.

SALGADO, A.A.R.; COLIN, F.; NALINI JR., H.A.; BRAUCHER, R.; VARAJÃO, A.F.D.C. \& VARAJÃO, C.A.C. O papel da denudação geoquímica no processo de erosão diferencial no Quadrilátero Ferrífero. R. Bras. Geomorfol., 5:55-69, 2004.

SALGADO, A.A.R.; BRAUCHER, R.; COLIN, F.; NALINI JR., H.A.; VARAJAO, A.F.D.C. \& VARAJAO, C.A.C. Denudation rates of the Quadrilátero Ferrífero (Minas Gerais, Brazil): Preliminary results from measurements of solute fluxes in rivers and in situ-produced cosmogenic 10Be. J. Geochem. Explor., 88:313-317, 2006.

SALGADO, A.A.R.; VARAJÃO, C.A.C.; COLIN F.; BRAUCHER, R.; VARAJÃO, A.F.D.C. \& NALINI JR., H.A. Study of the erosion rates in the upper Maracujá Basin (Quadrilátero Ferrífero/MG, Brazil) by the in situ produced cosmogenic 10Be method. Earth Surface Proc. Landforms, 32:905-911, 2007.

SALGADO, A.A.R.; BRAUCHER, R.; VARAJÃO, C.A.C.; COLIN, F.; VARAJÃO, A.F.D. \& NALINI JUNIOR, H.A Relief evolution of the Quadrilátero Ferrífero (Minas Gerais, Brazil) by means of (10Be) cosmogenic nuclei. Zeitschrift Geomorphol., 52:317-323, 2008.

SANTOS, M.C. Caracterização dos depósitos argilosos da porção centro-sul do Sinclinal Moeda, Quadrilátero Ferrífero, MG: Macromorfologia, micromorfologia, cristaloquímica, gênese e considerações industriais. Ouro Preto, Universidade Federal de Ouro Preto, 2003. 199p. (Tese de Doutorado)

SANTOS, M.D.C. \& VARAJÃO A.F.D.C. Sedimentation and Pedogenic features in a clay deposit in Quadrilátero Ferrífero, Minas Gerais, Brazil. An. Acad. Bras. Ci., 76:147$159,2004$.

SANTOS, M.C., VARAJÃO, A.F.D.C. \& YVON, J. Genesis of clayey bodies in Quadrilatero Ferrífero, Minas Gerais, Brazil. Catena, 55:277-291, 2004.

SCHOBBENHAUS, C., coord. Carta geológica do Brasil ao milionésimo; Folha Goiás (SD.22) Brasília, MME/DGM/ DNPM, 1975. 114p.

SILVA, A.M.; KUYUMJIAN, R.M. \& CHEMALE JR., F. Rochas básicas do Quadrilátero Ferrífero e Espinhaço Meridional: Estudos preliminares. R. Escola Minas, 45:60-62, 1992.
SPIER, C.A.; VASCONCELOS, P.M. \& OLIBEIRA, S.M.B. 40Ar/39Ar geochronological constraints on the evolution of lateritic iron deposits in the Quadrilátero Ferrífero, Minas Gerais, Brazil. Chem. Geol., 234:79-104, 2006.

SPRY, A. Metamorphic textures. Oxford, Pergamon Press, 1969. 342p.

STONE, J.O. Air pressure and cosmogenic isotope production. J. Geophys. Res., 105:23753-23759, 2000.

SUMMERFIELD, M.A. Global geomorphology: An introduction of the study of landforms. New York, Longman Scientific \& Technical, 1991. 537p.

TARDY, Y.; KOBILSHEK, B. \& PAQUET, H. Mineralogical composition and geographical distribution of African and Brasilian periatlantic laterites. The influence of continental drift and tropical paleoclimates during the past 150 million years and implications for India and Australia. J. Afr. Earth Sci., 12:283-295, 1991.

VARAJÃO, A.F.D.C.; BOULANGE, B. \& MELFI, A.J. The petrologic evolution of the facies in the kaolinite and bauxite deposits of Vargem dos Óculos, Quadrilátero Ferrífero, Minas Gerais, Brazil. Travaux, 19:137-146, 1989a.

VARAJÃO, A.F.D.C.; BOULANGE, B. \& MELFI, A.J. Caracterização das unidades morfológicas e formações superficiais nas adjacências das jazidas de caulinita e bauxita de Vargem dos Óculos, Quadrilátero Ferrífero, MG. R. Escola Minas, 42:21-14, 1989b.

VARAJÃO, A.F.D.C., BOULANGE, B. \& MELFI, A.J. Caracterização morfológica, mineralógica e química das fácies estruturais da jazida de caulinita de Vargem dos Óculos, Quadrilátero Ferrífero, MG. R. Bras. Geoci., 20:5$82,1990$.

VARAJÃO, A.F.D.C. \& SANTOS, M.C. Facies distribution and pedogenic evolution of the clayey deposit of Caxambu Hill, Minas Gerais, Brazil. In: INTERNATIONAL CLAY CONFERENCE - 2001 A CLAY OYISSEY, 12., Bahia Blanca, 2003. p.171-178.

VARAJÃO, A.F.D.C.; COSTA, L.A.; BOULANGÉ, B. \& MOREIRA, A.P.A. Colluvial features of the clayey deposits of the Moeda Syncline, Quadrilátero Ferrífero, Minas Gerais, Brazil. Zentralblatt Geol. Paläontol., 7/ 8:957-968, 2000a.

VARAJÃO, A.F.D.C.; GILKES, R.J. \& HART, R.D. The relationships between kaolinite crystal properties and the origin of materials for a Brazilian kaolin deposit. Clays Clay Miner., 49:44-59, 2001.

VARAJÃO, C.A.C. A questão da correlação das superfícies de erosão do Quadrilátero Ferrífero, Minas Gerais. R. Bras. Geoci., 21:138-145, 1991.

VARAJÃO; C.A.C.; RAMANAIDOU, E.; MELFI, A.J.; COLIN, F. \& NAHON, D. Alteração dos Itabiritos da Mina de Maquiné (Quadrilátero Ferrífero): Um exemplo de alteração isalterítica In: CONGRESSO BRASILEIRO DE GEOLOGIA, 39., Salvador, 1996. Anais. Salvador, Sociedade Brasileira de Geologia, 1996a. p.171-173. 
VARAJÃO, C.A.C.; RAMANAIDOU, E.; MELFI, A.J.; COLIN, F. \& NAHON, D. Martitização: Alteração supergênica da magnetita.. R. Escola Minas, 50:18-20, 1996b.

VARAJÃO, C.A.C.; RAMANAIDOU, E.; COLIN, F. \& NAHON, D. Gênese dos corpos de hematita compacta ("Hard Hematite Ores"): Metassomatismo, sedimentação ou alteração supergênica? R. Escola Minas, 50:40-43, 1997.
VARAJÃO, C.A.C.; COLIN, F.; VIEILLARD, P.; MELFI, A.J. \& NAHON, D. Early weathering of palladium gold under lateritic conditions, Maquiné Mine, Minas Gerais, Brazil. Appl. Geochem.,15:245-263, 2000b.

VARAJÃO, C.A.C.; BRUAND, A.; RAMANAIDOU, E.C. \& GILKES, R.J. Microporosity and reducibility of BIF hosted massive hematite ore, iron quadrangle, Brazil. An. Acad. Bras. Ci., 74:113-126, 2002. 